\title{
Insights into Nitric Oxide-Mediated Water Balance, Antioxidant Defence and Mineral Homeostasis in Rice (Oryza sativa L.) under Chilling Stress
}

\author{
Abdullah Al Mamun Sohag', Md. Tahjib-Ul-Arif ${ }^{1,2 *}$, Sonya Afrin ${ }^{2}$, Md Kawsar Khan ${ }^{3}$, Md. Abdul
} Hannan $^{1 *}$, Milan Skalicky ${ }^{4}$, Md Golam Mortuza ${ }^{1}$, Marian Brestic ${ }^{4}, 5$, M. Afzal Hossain ${ }^{1}$, Yoshiyuki Murata $^{2}$

1 Department of Biochemistry and Molecular Biology, Faculty of Agriculture, Bangladesh Agricultural University, Mymensingh-2202, Bangladesh; sohag2010bmb.sust@gmail.com (A.A.M.S.); gmortuza2003@yahoo.com (G.M.); mafzal.bau@gmail.com (M.A.Ho.)

2 Graduate School of Environmental and Life Science, Okayama University, Kita-ku, Okayama 700-8530, Japan; sonya.bau288@gmail.com (S.A.); muta@cc.okayama-u.ac.jp (Y.M.)

3 Department of Biochemistry and Molecular Biology, Shahjalal University of Science \& Technology, Sylhet-3114, Bangladesh; bmbkawsar@gmail.com (M.K.K.)

4 Department of Botany and Plant Physiology, Faculty of Agrobiology, Food, and Natural Resources Czech University of Life Sciences, 16500 Prague, Czech Republic; marian.brestic@uniag.sk (M.B.); skalicky@af.czu.cz (M.S.)

5 Department of Plant Physiology, Faculty of Agrobiology and Food Resources, Slovak University of Agriculture, 94976 Nitra, Slovakia

* Correspondence: Md. Abdul Hannan (hannanbmb@bau.edu.bd) \& Md. Tahjib-Ul-Arif (tahjib@bau.edu.bd)

\section{Running title: Nitric Oxide-Mediated Chilling Stress Tolerance in Rice}

Abstract: Being a chilling-sensitive staple crop, rice (Oryza sativa L.) is vulnerable to climate change. The competence of rice to withstand chilling stress should, therefore, be enhanced through technological tools. The present study employed chemical intervention like application of sodium nitroprusside (SNP) as nitric oxide (NO) donor and elucidated the underlying molecular mechanisms of NO-mediated chilling tolerance in rice. At germination stage, germination indicators were interrupted by chilling stress $\left(5.0 \pm 1.0^{\circ} \mathrm{C}\right.$ for $8 \mathrm{~h}$ day $^{-1}$ ), while pretreatment with $100 \mu \mathrm{M}$ SNP markedly improved the indicators. At seedling stage (14-dayold), chilling stress caused stunted growth with visible toxicity along with alteration of biochemical markers, for example, increase in oxidative stress markers (superoxide, hydrogen peroxide, and malondialdehyde) and osmolytes (total soluble sugar; proline and soluble protein content, SPC), and decrease in chlorophyll (Chl), relative water content (RWC), and antioxidants. However, NO application attenuated toxicity symptoms with improving growth performance which might be attributed to enhanced activities of antioxidants, mineral contents, Chl, RWC and SPC. Furthermore, principal component analysis indicated that water imbalance and increased oxidative damage were the main contributors to chilling injury, whereas NO-mediated mineral homeostasis and antioxidant defense were the critical determinants for chilling tolerance in rice. Collectively, our findings revealed that NO protects against chilling stress through valorizing cellular defense mechanisms, suggesting that exogenous application of NO could be a potential tool to evolve cold tolerance as well as climate resilience in rice.

Keywords: antioxidant system; chilling stress; mineral homeostasis; nitric oxide; oxidative stress; rice 


\section{Introduction}

Climate change noticeably alters the distribution of temperature variability [1], which results in more frequent cold stress events during the crop growing seasons [2]. Prolonged exposure (i.e. several days to weeks) of plants to chilling temperature exerts a severe threat to physiological, biochemical, and molecular processes of plants which results in impairment on seed germination, plant growth and development [2,3]. In semi-arid climates, plants are often exposed to extreme temperatures including hot day and cold night - this fluctuation in temperature results in an additional threat to the plants [4].

In plants, the preliminary symptoms of chilling stress include disruption of plant-water relationships, reduced nutrient uptake, destruction of photosynthetic pigments, change in protein structures, and enzyme activities, which, in turn, exert a serious threat to cell survival resulting in programmed cell death [5,6]. Furthermore, the perturbation in photosynthesis increases the production of excessive reactive oxygen species (ROS) [singlet oxygen $\left({ }^{1} \mathrm{O}_{2}\right)$, superoxide anion $\left(\mathrm{O}_{2}{ }^{-}\right)$, hydrogen peroxide $\left(\mathrm{H}_{2} \mathrm{O}_{2}\right)$, and hydroxyl radical $\left.\left(\mathrm{OH}^{-}\right)\right]$through Fenton Haber-Weiss reactions [7,8]. Excessive ROS accumulation is responsible for the oxidation of vital biomolecules [9]. Thus, scavenging of these harmful ROS is crucial for the survival of plants, which is mainly accomplished by the antioxidants. The increased antioxidants, therefore, confer tolerance in the plants during chilling stress $[6,10,11]$. Plants acquired various kinds of defense strategies to cope with the stress-induced adversities, which includes enzymatic antioxidants (catalase, CAT; superoxide dismutase, SOD; peroxidase, POX etc.), non-enzymatic antioxidants (ascorbate, AsA; carotenoids, and phenolic compounds etc.), osmolytes (proline, soluble sugars and proteins) $[12,13,14]$. On the contrary, any imbalance of antioxidants, osmoregulation, and essential minerals homeostasis lead to the impairment of plant defence mechanisms which results in weakening of plant physiological processes [7]. In this context, chemical priming has been considered as an alternative strategy for improving abiotic stress resistance of plants [15].

Augmenting the defensive responses of plants can minimize the chilling-induced damage, which can be attained by applying exogenous signalling molecules [16]. Nitric oxide (NO), an enormously diffusible and a versatile bioactive inter- and intra-cellular signalling compound, found to be involved in seed germination, water balance, mineral adjustment, gene regulation, and upregulation of antioxidant enzyme activities in plants $[17,18,19]$. NO networks with other hormones (abscisic acid, auxins, brassinosteroids, cytokinins, ethylene, gibberellins, jasmonates, and salicylic acid, etc.) and signalling molecules ( $\mathrm{Ca}^{2+}$, glutathione, and ROS), that alter the developmental activities and stress tolerance of plants [19]. Moreover, NO can possess an energetically more advantageous electron structure, by gaining or losing an electron, to neutralize toxic ROS in the plant cell $[19,20]$. Furthermore, NO can counteract oxidative stress by directly acting as an antioxidant, regulating the osmotic balance, protecting membrane lipid and stimulating the gene expression of the antioxidant enzymes under various abiotic stress conditions $[18,19,20]$. In recent years, the exogenous applications of NO showed a protective effect against chilling stress in several plants such as cucumber (Cucumis sativus) [21], wheat (Triticum aestivum) [22] and Chinese cabbage (Brassica rapa subsp. Pekinensis) [23]. Additionally, the exogenous application of NO displayed protective effect in salt-stressed chickpea (Cicer arietinum L.) [24] and drought-stressed rapeseed (Brassica napus) [25]. However, to the best of our knowledge, whether exogenous applications of NO can alleviate chilling-induced oxidative stress in rice plants, has not been reported yet.

Rice is a staple food for more than 60 per cent of the world population [26] and is widely cultivated in tropical, subtropical and temperate climate zones [27]. The optimum temperature for rice cultivation fluctuates between $25^{\circ} \mathrm{C}-35^{\circ} \mathrm{C}$ which indicates the reason behind the susceptibility of rice to chilling temperature compared to other cereal crops [28,29]. About $10 \%$ of rice cultivable lands are affected by chilling stress $[3,27,29]$. Particularly during the seedling stage, chilling causes necrotic lesions on leaves, yellowing symptoms, delay leaf development and induce wilting of leaves $[3,27]$ which results in mass 
death of rice seedlings in the seedbed. For instance, in the northern region of Bangladesh, cold is usually more substantial (around $2.6^{\circ} \mathrm{C}$ in January) than other parts of the country and damages rice seedbeds during the winter season $[29,30,31]$. Protecting rice seedlings from this harsh cold spell is, therefore, necessary for higher rice production.

In this study, firstly, we investigated whether NO mitigates chilling stress in rice both at the germination and seedling stages. Secondly, we also investigated the protective functions of NO in enhancing chilling tolerance of rice seedlings by examining the morphological, physiological and biochemical mechanisms through the evaluation of the following features: (i) germination indices, (ii) plant growth attributes and biomass production, (iii) mineral homeostasis, (iv) photosynthetic pigment, (v) various types of osmolyte status, (vi) chilling-induced oxidative injury in terms of elevated ROS levels and lipid peroxidation, and (vii) enhancement of antioxidant defense system.

\section{Materials and Methods}

\subsection{Germination Stage Experiment}

BRRI dhan29, a cold-sensitive, high-yielding and widely cultivated rice in Bangladesh, was used in this experiment. For surface sterilization, seeds were soaked in $2.5 \%$ sodium hypochlorite $+2.0 \%$ Tween20 solution for 15 minutes, followed by washed with double distilled water $\left(\mathrm{ddH}_{2} \mathrm{O}\right)$ four times. After that,

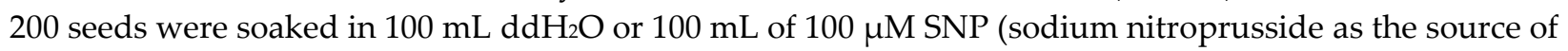
$\mathrm{NO}$ ) solution and kept in dark at $25^{\circ} \mathrm{C}$. After $24 \mathrm{~h}$ of imbibition, $\mathrm{ddH}_{2} \mathrm{O}$ or SNP soaked seeds transferred in two Petri dishes (two pieces of filter papers were placed in each Petri dish with a diameter of $9 \mathrm{~cm}$, and an equal volume of $\mathrm{ddH}_{2} \mathrm{O}$ was added to soak the paper) each with 100 seeds. Then one batch of Petri dishes was kept in normal condition and others in chilling stress. Therefore, the study comprised of four treatments as follows " $\mathrm{C}^{\prime}, 0 \mathrm{~h}$ chilling day ${ }^{-1}+0 \mu \mathrm{M} \mathrm{SNP}$ (control); " $\mathrm{CH}^{\prime}, 8 \mathrm{~h}$ chilling day ${ }^{-1}+0 \mu \mathrm{M}$ SNP; "SNP", 0 h chilling day ${ }^{-1}+100 \mu \mathrm{M}$ SNP; and "CH + SNP", 8 h chilling day ${ }^{-1}+100 \mu \mathrm{M}$ SNP. The "C" and "SNP" levelled Petri dishes were kept in the dark at $29^{\circ} \mathrm{C}$, whereas " $\mathrm{CH}^{\prime}$ and " $\mathrm{CH}+\mathrm{SNP}^{\prime}$ levelled Petri dishes were kept at the cold chamber for $8 \mathrm{~h} \mathrm{day}^{-1}$ (cold chamber at night, $10.00 \mathrm{PM}-6.00 \mathrm{AM}, 5.0 \pm 1.0^{\circ} \mathrm{C}$ ). After $8 \mathrm{~h}$ of chilling treatment, " $\mathrm{CH}^{\prime}$ and " $\mathrm{CH}+\mathrm{SNP}$ " levelled Petri dishes were transferred to dark daily at $29^{\circ} \mathrm{C}$. However, seeds were considered as germinated when the radical reached $2 \mathrm{~mm}$ in length. From $2^{\text {nd }}$ day after incubation (DAI), number of germinated seeds was recorded up to $5^{\text {th }}$ DAI and by using these germination counts, several germination indices were determined, such as final germination percentage (FGP), germination rate index (GRI), coefficient of velocity of germination (CVG), mean germination time (MGT) [32] and vigor index (VI) [33]. Moreover, the radicle length (RaL), plumule length (PL), radicle fresh weight $(\mathrm{RaFW})$, and plumule fresh weight $(\mathrm{PFW})$ were recorded at $6^{\text {th }}$ DAI.

\subsection{Seedling Stage Experiment}

Sterilized seeds were imbibed in $\mathrm{dH}_{2} \mathrm{O}$ for $24 \mathrm{~h}$ followed by incubated in the dark at $29^{\circ} \mathrm{C}$ for germination. One hundred and fifty germinated rice seeds were sown in $350 \mathrm{~mL}$ plastic pot containing $\mathrm{ddH}_{2} \mathrm{O}$. From the $3^{\text {rd }}$ day of sowing, the seedlings were grown in modified Cooper's nutrient solution [34]. The nutrient solution was prepared by adding the following to $10 \mathrm{~L}$ of distilled water; $\mathrm{KH}_{2} \mathrm{PO}_{4}(2.63 \mathrm{~g})$, $\mathrm{KNO}_{3}(5.83 \mathrm{~g}), \mathrm{Ca}\left(\mathrm{NO}_{3}\right)_{2} \cdot 4 \mathrm{H}_{2} \mathrm{O}(10.03 \mathrm{~g}), \mathrm{FeSO}_{4} \cdot 7 \mathrm{H}_{2} \mathrm{O}(2.00 \mathrm{~g}), \mathrm{MgSO}_{4} \cdot 7 \mathrm{H}_{2} \mathrm{O}(0.79 \mathrm{~g}), \mathrm{MnSO}_{4}(0.061 \mathrm{~g}), \mathrm{H}_{3} \mathrm{BO}_{3}$ $(0.017 \mathrm{~g}), \mathrm{CuSO}_{4} \cdot 5 \mathrm{H}_{2} \mathrm{O}(0.004 \mathrm{~g}), \mathrm{Na}_{2} \mathrm{MoO}_{4}(0.003 \mathrm{~g}), \mathrm{ZnSO}_{4} \cdot 7 \mathrm{H}_{2} \mathrm{O}(0.0044 \mathrm{~g})$. The experiment was conducted in a growth chamber set to a constant temperature of $25 \pm 2{ }^{\circ} \mathrm{C}$ and relative humidity of $65-70 \%$, at the Department of Biochemistry and Molecular Biology, Bangladesh Agricultural University, Mymensingh. The nutrient solution was replaced at 3-day intervals throughout the experiment. 
The 14-day old rice seedlings were treated with $100 \mu \mathrm{M}$ SNP in nutrient solution for three days. Moreover, seedlings were treated with freshly prepared $100 \mu \mathrm{M}$ SNP by the foliar application (10 mL spray${ }^{1}$ pot $^{-1}$ ) at 12:00 PM until the end of the experiment. The control plants were sprayed with $\mathrm{ddH}_{2} \mathrm{O}$. The Tween-20 $(0.1 \%, \mathrm{v} / \mathrm{v})$ was added both with SNP and water to ensure the maximum adherence of SNP and water to the leaves of the rice plant. After three days pretreatment, 17-day old SNP-pretreated and nontreated rice seedlings were subjected to chilling stress every day (induced by keeping in a cold chamber at night for $8 \mathrm{~h} \mathrm{day}^{-1}, 10.00 \mathrm{PM}-6.00 \mathrm{AM}, 5.0 \pm 1.0^{\circ} \mathrm{C}$ ) followed by recovery at $25^{\circ} \mathrm{C}$. Control and SNP treated non-stressed seedlings were kept at normal growth conditions throughout the experimental period. Therefore, the treatment combinations were the same as the germination stage experiments. The experiment was conducted using a randomized complete block design with three independent replicates for each treatment. After 8 days of growth under the above conditions, 25-day-old rice plants were harvested to measure different morpho-physiological and biochemical parameters.

\subsection{Analysis of Plant Growth Parameters and Relative Water Content}

The length from the shoot base to the leaf tip was measured for shoot length (SL) determination. Likewise, the root length (RL) was determined by measuring the length from the root base to the root tip. From each experiment, 25 seedlings were collected and weighed to determine the fresh weight (FW). The dry weight (DW) of shoot and root was determined after oven drying at $60^{\circ} \mathrm{C}$ for four days. The FWs and DWs of shoots and roots were expressed as $\mathrm{mg}$ seedling ${ }^{-1}$. The relative water content (RWC) of the rice leaves was measured by the method previously described [35].

\subsection{Determination of Photosynthetic Pigment, Carotenoids, and Total Soluble Protein}

Chlorophylls (Chl) and carotenoids extraction and determined were done according to the method of Lichtenthaler [36]. Soluble protein content (SPC) was determined by the method developed by Bradford [37] with some modifications. Leaf tissues of rice plants were homogenized with $0.1 \mathrm{M} \mathrm{NaOH}$ and vortexed for $30 \mathrm{~s}$ followed by centrifuged at $5000 \times \mathrm{g}$. Then $100 \mu \mathrm{L}$ of supernatant from the extract was added in $5 \mathrm{~mL}$ of Bradford reagent and was incubated for $25 \mathrm{~min}$. Finally, absorbance was taken at $595 \mathrm{~nm}$. The SPC of the samples were determined from the standard curve prepared using casein.

\subsection{Determination of $\mathrm{H}_{2} \mathrm{O}_{2}$, Malondialdehyde Content, and In Situ $\mathrm{O}_{2}^{\circ-}$}

The levels of $\mathrm{H}_{2} \mathrm{O}_{2}$ in leaves of rice seedlings were determined by following the method of Velikova et al. [38], using an extinction coefficient of $0.28 \mu \mathrm{M}^{-1} \mathrm{~cm}^{-1}$. Malondialdehyde (MDA) content was measured in rice leaves according to the method of Heath and Packer [39], using an extinction coefficient of $155 \mathrm{mM}^{-1} \mathrm{~cm}^{-1}$. Superoxide $\left(\mathrm{O}_{2}^{\circ-}\right)$ was detected histochemically using nitroblue tetrazolium (NBT) according to the method of Tahjib-Ul-Arif et al. [40].

\subsection{Measurement of Proline Content, Total Soluble Sugars, Total Phenolic Compounds, and Ascorbate Content}

The method of Zhang and Huang [41] with minor modifications was used to measure the proline content of rice leaves. Total soluble sugars (TSS) was determined using the modified anthrone method as previously reported by Ciha and Brun [42]. Dried shoot samples $(0.3 \mathrm{~g})$ were extracted with $80 \%$ ethanol, and the resultant extract was filtered. Then $1.0 \mathrm{~mL}$ of diluted extract was mixed with $4 \mathrm{~mL}$ of $2 \%$ anthrone solution and the mixture was then heated for $10 \mathrm{~min}$ and then cooled on ice. The absorbance of the solution was then measured at $620 \mathrm{~nm}$ using a UV-VIS spectrophotometer (Shimadzu, UV-1201, Kyoto, Japan). The TSS contents of the samples were determined from the standard curve prepared using glucose. 
The total phenolic compounds (TPC) was determined according to the method of Singleton and Rossi [43], using the Folin-Ciocalteu reagent. The AsA content was determined according to the method of Tahjib-Ul-Arif et al. [44].

\subsection{Assay of Antioxidant Enzyme Activities}

The activities of antioxidant enzymes were determined from the $3^{\text {rd }}$ leaves of rice seedlings. Fresh leaf samples $(0.05 \mathrm{~g})$ were homogenized using pre-chilled mortar and pestle with $1.0 \mathrm{~mL}$ of $50 \mathrm{mM}$ potassium phosphate buffer ( $\mathrm{pH} 8.0)$ to extract leaf enzymes. The homogenates were centrifuged at $11,500 \times \mathrm{g}$ for $10 \mathrm{~min}$ and the resultant supernatants were collected to analyze the activity of CAT (EC 1.11.1.6) [45], APX (EC 1.11.1.11) and POX (EC: 1.11.1.7) [46]. All procedures were carried out at $4^{\circ} \mathrm{C}$ and all of the spectrophotometric assays were performed using a UV-VIS spectrophotometer (Shimadzu, UV-1201, Kyoto, Japan).

\subsection{Determination of $\mathrm{Na}^{+}, \mathrm{K}^{+}, \mathrm{Ca}^{2+}$ and $\mathrm{Mg}^{2+}$ Content}

Twenty five-day-old rice shoots were harvested and washed rigorously with deionized water to eliminate surface contaminants. Seedlings were then oven-dried at $70^{\circ} \mathrm{C}$ for four days, and the finely powdered plant material was digested with $\mathrm{HNO}_{3}: \mathrm{HClO}_{4}(2: 1 \mathrm{v} / \mathrm{v})$ mixture at $220^{\circ} \mathrm{C}$ for $2 \mathrm{~h}$ according to the method of Tahjib-Ul-Arif et al. [47]. $\mathrm{Na}^{+}$and $\mathrm{K}^{+}$contents were quantified by flame photometry (Jencon PFP 7, JENCONS-PLS, UK) and $\mathrm{Ca}^{2+}$ and $\mathrm{Mg}^{2+}$ contents were measured by titration, using disodium ethylene diamine tetra acetate, according to the methods of Schmid and Reilley [48].

\subsection{Statistical Analysis}

A one-way analysis of variance followed by Tukey's test was performed using Minitab 17.0. MetaboAnalyst 4.0 was used for cluster analysis and the generation of heatmap from normalized mean values [49]. The PCA analysis was done in $\mathrm{R}$ version 3.5.2 using the packages ggplot2, factoextra, and FactoMineR [50,51]

\section{Results}

\subsection{Exogenous NO improved germination parameters of rice seeds under chilling stress}

The protective role of $\mathrm{NO}$ on the germination capacity of rice seeds under chilling stress was evaluated by determining the PL, PFW, FGP, GRI, CVG and VI. Under chilling stress condition, PL, PFW, FGP, GRI, CVG and VI were markedly decreased by $29.09 \%, 47.06 \%, 24.38 \%, 55.17 \%, 32.32 \%$, and $68.25 \%$, respectively, compared with that of the control treatment (Table 1). On the other hand, exogenous application of SNP on chilling-stressed seedlings elevated the PL, PFW, FGP, GRI, CVG and VI by 36.75\%, $55.55 \%, 19.67 \%, 48.25 \%, 18.65 \%$ and $103.08 \%$, respectively, whereas declined MGT (by $12.8 \%$ ) relative to only chilling-stressed rice seedlings (Table 1). Moreover, compared with control, RaL, RaFW, and MGT were increased significantly by $46.15 \%, 38.89 \%$ and $42.26 \%$ in response to only chilling-stressed treatment (Table 1). 
Table 1 Effects of exogenous sodium nitroprusside (SNP) on germination indices and growth parameters of rice at germination stage grown under chilling stress

\begin{tabular}{|c|c|c|c|c|c|c|c|c|c|}
\hline \multirow[b]{2}{*}{ Treatment } & \multicolumn{5}{|c|}{ Germination indices } & \multicolumn{4}{|c|}{ Growth parameters } \\
\hline & $\begin{array}{c}\text { FGP } \\
(\%)\end{array}$ & $\begin{array}{l}\text { MGT } \\
\text { (days) }\end{array}$ & $\begin{array}{c}\text { GRI } \\
\left(\% \text { day }^{-1}\right)\end{array}$ & $\begin{array}{c}\text { CVG } \\
\left(\% \text { day }^{-1}\right)\end{array}$ & VI & $\begin{array}{c}\text { PL } \\
(\mathrm{cm})\end{array}$ & $\begin{array}{l}\text { RaL } \\
(\mathrm{cm})\end{array}$ & $\begin{array}{l}\text { PFW } \\
\text { (mg) }\end{array}$ & $\begin{array}{c}\text { RaFW } \\
\text { (mg) }\end{array}$ \\
\hline C & $80.67 \pm 1.09^{b}$ & $2.07 \pm 0.0^{c}$ & $52.79 \pm 0.6^{\mathrm{b}}$ & $48.47 \pm 0.5^{\mathrm{b}}$ & $290.27 \pm 1.0^{\mathrm{b}}$ & $5.50 \pm 0.05^{\mathrm{a}}$ & $3.90 \pm 0.3^{b}$ & $51.00 \pm 1.69^{a}$ & $6.00 \pm 0.05^{b}$ \\
\hline $\mathrm{CH}$ & $61.00 \pm 1.24^{\mathrm{d}}$ & $2.94 \pm 0.0^{\mathrm{a}}$ & $23.67 \pm 1.0^{\mathrm{d}}$ & $32.81 \pm 0.6^{\mathrm{d}}$ & $92.16 \pm 3.48^{\mathrm{d}}$ & $3.90 \pm 0.09^{\mathrm{b}}$ & $5.70 \pm 0.1^{\mathrm{a}}$ & $27.00 \pm 1.24^{\mathrm{b}}$ & $8.33 \pm 0.27^{a}$ \\
\hline SNP & $86.67 \pm 1.19^{a}$ & $1.85 \pm 0.0^{\mathrm{d}}$ & $59.20 \pm 1.09^{a}$ & $51.60 \pm 0.6^{\mathrm{a}}$ & $325.59 \pm 6.6^{\mathrm{a}}$ & $5.50 \pm 0.05^{\mathrm{a}}$ & $3.20 \pm 0.1^{\mathrm{b}}$ & $47.00 \pm 2.05^{\mathrm{a}}$ & $6.33 \pm 0.27^{b}$ \\
\hline $\mathrm{CH}+\mathrm{SNP}$ & $73.00 \pm 0.47^{c}$ & $2.56 \pm 0.0^{\mathrm{b}}$ & $35.09 \pm 0.19^{c}$ & $38.92 \pm 0.3^{c}$ & $187.16 \pm 2.9^{c}$ & $5.33 \pm 0.05^{\mathrm{a}}$ & $5.33 \pm 0.0^{\mathrm{a}}$ & $42.00 \pm 1.41^{\mathrm{a}}$ & $7.33 \pm 0.27^{\mathrm{ab}}$ \\
\hline
\end{tabular}

Data presented are means of three independent replicates \pm standard errors $(n=3)$. Different letters in each column represent significant differences at $P<0.05$ (Tukey's honest significant differences test). " $\mathrm{C}^{\prime}, 0 \mathrm{~h}$ chilling day ${ }^{-1}+0 \mu \mathrm{M}$ SNP (control); " $\mathrm{CH}^{\prime}$, 8 h chilling day ${ }^{-1}+0 \mu \mathrm{M}$ SNP; "SNP", 0 h chilling day ${ }^{-1}+100 \mu \mathrm{M}$ $\mathrm{SNP}$; and " $\mathrm{CH}+\mathrm{SNP}^{\prime}$ ", $8 \mathrm{~h}$ chilling day ${ }^{-1}+100 \mu \mathrm{M}$ SNP. Final germination percentage (FGP); mean germination time (MGT); germination rate index (GRI); coefficient of velocity of germination (CVG); vigor index (VI); plumule length (PL); radicle length (RaL); plumule fresh weight (PFW) and radicle fresh weight (RaFW).

\subsection{Exogenous NO enhanced growth, biomass and photosynthetic pigments of rice plants under chilling stress}

To determine whether SNP was involved in improving the toxic effects of chilling, we monitored the growth parameters of rice seedlings. Rice seedlings treated with only chilling displayed a significant reduction in SL, SFW, RFW, SDW and RDW (by 17.92\%, 41.04\%, 49.22\%, 51.55\%, and 44.32\%, respectively) as compared with that of the non-stressed seedlings (Table 2). However, exogenous application of SNP to chilling-stressed plants relieved the lethal effects of chilling stress by significantly enhancing the SL, SFW, RFW, SDW and RDW (by 22.99\%, 57.09\%, 50.78\%, 29.075\%, and 86.92\%, respectively) in comparison with that of the only chilling-stressed plants. Exogenous application SNP on chilling free rice seedlings showed no significant effect on the growth of rice seedlings except the SFW compared with the control (Table 2).

Table 2 Effects of exogenous sodium nitroprusside (SNP) on growth and photosynthetic pigments of rice seedlings grown under chilling stress

\begin{tabular}{|c|c|c|c|c|c|c|c|c|c|}
\hline \multirow{2}{*}{ Treatment } & \multirow{2}{*}{$\begin{array}{l}\text { Shoot } \\
\text { Length } \\
\text { (cm } \\
\text { seedling-1) }\end{array}$} & \multirow{2}{*}{$\begin{array}{c}\text { Root } \\
\text { Length } \\
(\mathrm{cm} \\
\text { seedling-1) }\end{array}$} & \multicolumn{2}{|c|}{$\begin{array}{l}\text { Fresh weight } \\
\left(\mathrm{mg} \mathrm{seedling}^{-1}\right)\end{array}$} & \multicolumn{2}{|c|}{$\begin{array}{c}\begin{array}{c}\text { Dry weight } \\
(\mathrm{mg} \text { seedling-1) }\end{array} \\
\end{array}$} & \multicolumn{3}{|c|}{$\begin{array}{l}\text { Chlorophyll content } \\
\left(\mathrm{mg} \mathrm{g}^{-1} \text { FW) }\right.\end{array}$} \\
\hline & & & Shoot & Root & Shoot & Root & Chl $a$ & Chl $b$ & Chl $a+b$ \\
\hline C & $17.67 \pm 0.36^{a}$ & $8.17 \pm 0.49^{\mathrm{ab}}$ & $203.67 \pm 0.72^{\mathrm{a}}$ & $27.00 \pm 0.47^{a}$ & $12.83 \pm 0.36^{a}$ & $8.53 \pm 0.53^{a}$ & $0.27 \pm 0.03^{a}$ & $0.09 \pm 0.01^{\mathrm{ab}}$ & $0.37 \pm 0.03^{a}$ \\
\hline $\mathrm{CH}$ & $14.50 \pm 0.24^{\mathrm{b}}$ & $10.00 \pm 0.47^{\mathrm{ab}}$ & $98.67 \pm 1.44^{\mathrm{d}}$ & $15.03 \pm 0.65^{c}$ & $7.57 \pm 0.30^{c}$ & $4.33 \pm 0.35^{\mathrm{b}}$ & $0.06 \pm 0.01 \mathrm{~b}$ & $0.02 \pm 0.01^{\mathrm{c}}$ & $0.08 \pm 0.02^{c}$ \\
\hline SNP & $18.47 \pm 0.42^{\mathrm{a}}$ & $6.77 \pm 0.99^{b}$ & $190.67 \pm 2.41^{b}$ & $25.67 \pm 0.98^{\mathrm{ab}}$ & $12.97 \pm 0.16^{\mathrm{a}}$ & $7.03 \pm 0.26^{\mathrm{a}}$ & $0.35 \pm 0.02 \mathrm{a}$ & $0.13 \pm 0.02^{\mathrm{a}}$ & $0.48 \pm 0.01^{\mathrm{a}}$ \\
\hline
\end{tabular}

Data presented are means of three replicates \pm standard errors $(n=3)$. Different letters in each column represent significant differences at $P<0.05$ (Tukey's honest significant differences test). " $\mathrm{C}^{\prime}, 0 \mathrm{~h}$ chilling day${ }^{1}+0 \mu \mathrm{M}$ SNP (control); “ $\mathrm{CH}^{\prime}, 8 \mathrm{~h}$ chilling day ${ }^{-1}+0 \mu \mathrm{M}$ SNP; "SNP", 0 h chilling day ${ }^{-1}+100 \mu \mathrm{M}$ SN; and "CH+SNP", 8 h chilling day ${ }^{-1}+100 \mu \mathrm{M}$ SNP. 
We determined the Chl content of rice leaves to know the role of SNP in protecting photosynthetic machinery under chilling stress. Chilling treatment caused a significant decrease in Chl $a$, Chl $b$ and Chl $a+b$ contents (by $76.99 \%, 82.89 \%$ and $78.51 \%$, respectively) compared with that of control (Table 2). On the contrary, exogenously applied SNP significantly alleviated the inhibitory effects of chilling (by $157.54 \%$, $286.21 \%$, and $183.85 \%$ ) relative to only chilling-stressed treatment. Also, a significant elevation of Chl $a$, Chl $b$ and $\mathrm{Chl} a+b$ content, with relative to the control, was observed in SNP-treated rice seedlings without chilling stress (Table 2).
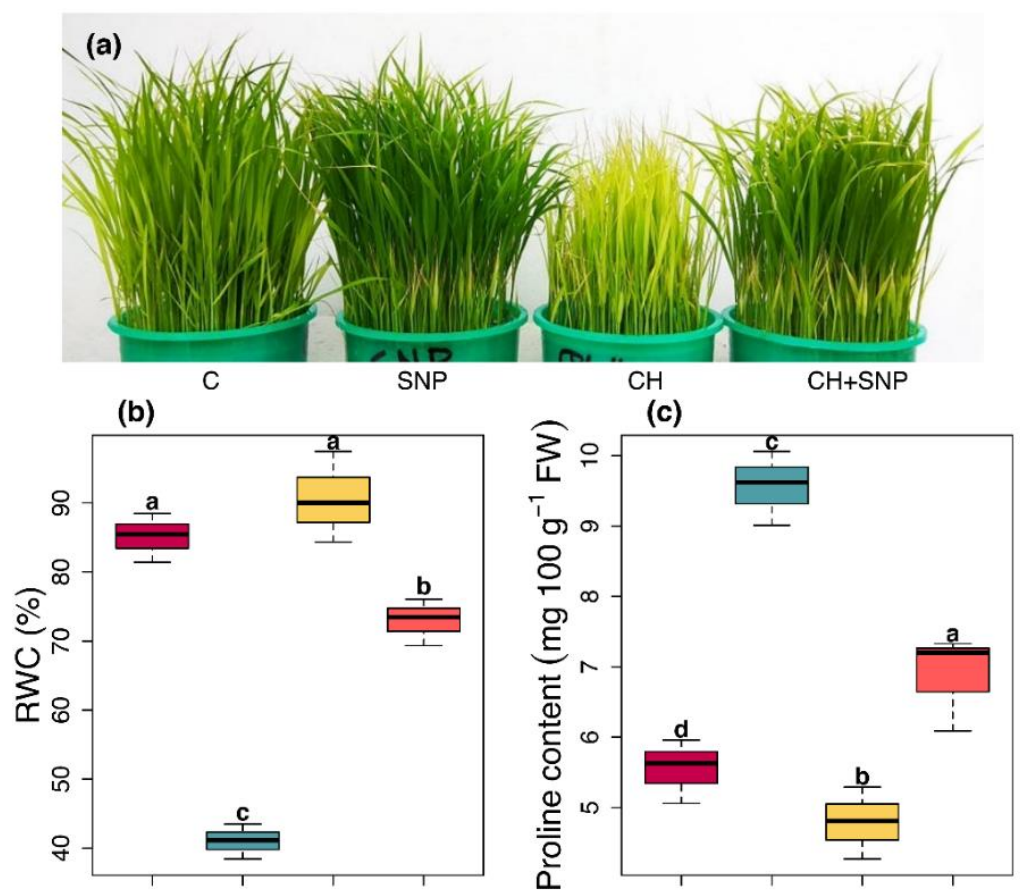

(d)

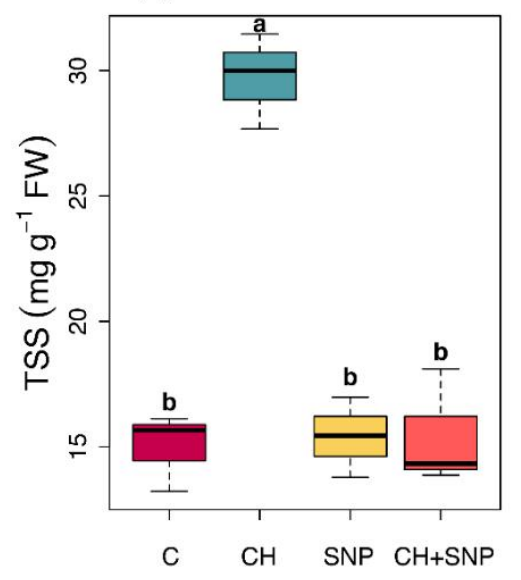

(e)

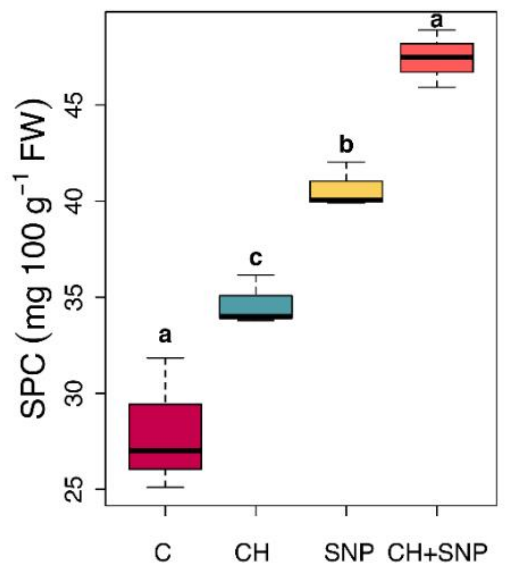

Figure 1. Effects of exogenous sodium nitroprusside (SNP) on (a) phenotype, (b) relative water content (RWC), (c) proline content, (d) total soluble sugar (TSS), and (e) soluble protein content (SPC) of rice seedlings grown under normal or chilling stress condition for 8 days. Data represented as the means of three independent replicates for each treatment $(n=3)$. The vertical bars indicate standard errors. Different letters 
on the top of each bar denote statistically significant differences at $P<0.05$, based on Tukey's test. " $\mathrm{C}^{\prime}, 0 \mathrm{~h}$ chilling day ${ }^{-1}+0 \mu \mathrm{M}$ SNP (control); " $\mathrm{CH}^{\prime}$, 8 h chilling day ${ }^{-1}+0 \mu \mathrm{M}$ SNP; "SNP", 0 h chilling day ${ }^{-1}+100 \mu \mathrm{M}$ $\mathrm{SNP}$; and "CH+SNP", 8 h chilling day ${ }^{-1}+100 \mu \mathrm{M}$ SNP.

3.3. Exogenous NO improved phenotype, water relation and regulated osmolyte status of rice plants under chilling stress

Application of SNP on chilling-stressed rice seedling improved the phenotype (Figure 1a; the photograph was taken on day $25^{\text {th }}$ of the experiment). Chilling stress-induced yellowing symptoms on the leaves and deteriorated the plant growth in terms of shoot length of rice seedlings (Figure 1a). On the other hand, exogenous application of SNP mitigated the lethal effects of chilling stress as displayed improved phenotypes of rice seedlings (Figure 1a). Chilling stress declined the RWC of rice plants by $44.32 \%$ but increased proline, TSS and SPC by $72.31 \%, 98.07 \%$ and $23.82 \%$ compared with that of the non-stressed treatment (Figure 1b-e). However, a notable increase in RWC and SPC (77.75\% and $36.92 \%$, respectively), but a marked decline in proline and TSS (28.12\% and 48.05\%, respectively), were recorded in SNP-treated chilling-stressed seedlings compared with only chilling-stressed rice seedlings (Figure 1b-e). Moreover, the application of SNP to non-stressed rice seedlings resulted in enhanced SPC (by 45.30\%) but in declined proline content (by 13.69\%) as compared with that of control rice seedlings (Figure 1b, e).

3.4. Exogenous NO decreased lipid peroxidation, ROS accumulation and enhanced activities of antioxidant enzyme of rice plants under chilling stress

To examine whether exogenous SNP mitigated chilling-induced excess ROS accumulation and membrane damage in rice seedlings, we examined $\mathrm{O}_{2}{ }^{\bullet-}, \mathrm{H}_{2} \mathrm{O}_{2}$ and MDA contents. Superoxide $\left(\mathrm{O}_{2}{ }^{\bullet-}\right)$ was visualized histochemically in leaves by NBT staining. Chilling-stressed rice seedlings showed the highest $\mathrm{O}_{2}{ }^{*-}$ accumulation (observed as dark blue spots within the leaf blade) (Figure 2a). In contrast, SNP-treated chilling-stressed seedlings showed less $\mathrm{O}_{2}{ }^{-}$-accumulation as compared with seedlings treated with chilling stress only (Figure 2a).

The production of MDA and $\mathrm{H}_{2} \mathrm{O}_{2}$ was markedly increased by $85.74 \%$ and $197.63 \%$ at only chilling treatment as compared with that of the control treatment (Figure 2b, c). Supplying SNP to the chillingstressed rice seedlings resulted in reductions in MDA and $\mathrm{H}_{2} \mathrm{O}_{2}$ production by $25.55 \%$ and $36.91 \%$ in comparison with only chilling-stressed rice seedlings (Figure $2 b, c)$. Furthermore, under non-stressed conditions, exogenous SNP exhibited no significant increase in the contents of MDA and $\mathrm{H}_{2} \mathrm{O}_{2}$ (Figure $2 \mathrm{~b}$, c).

The rice seedlings exposed to chilling stress had increased APX and POX activity by $29.75 \%$ and $94.19 \%$ at chilling treatment, respectively, as compared with that of the control (Figure 3b, c). In contrast, SNP supplementation to chilling-stressed seedlings further showed enhancement of APX and POX activity by $28.40 \%$ and $31.80 \%$, respectively, as compared with only chilling-stressed seedlings (Figure $3 \mathrm{~b}, \mathrm{c}$ ). The significant declination in CAT activity by $40.60 \%$ was recorded at chilling treatment relative to that of the control treatment. The SNP application to the chilling-stressed rice seedling elevated the CAT activity by $62.68 \%$ compared with only chilling-stressed seedlings (Figure 3a). Moreover, in non-stressed plants, the application of SNP enhanced CAT, APX, and POX activity significantly by $13.60 \%, 94.71 \%$, and $55.01 \%$ in comparison with that of the control seedlings (Figure 3a-c). 
(a)

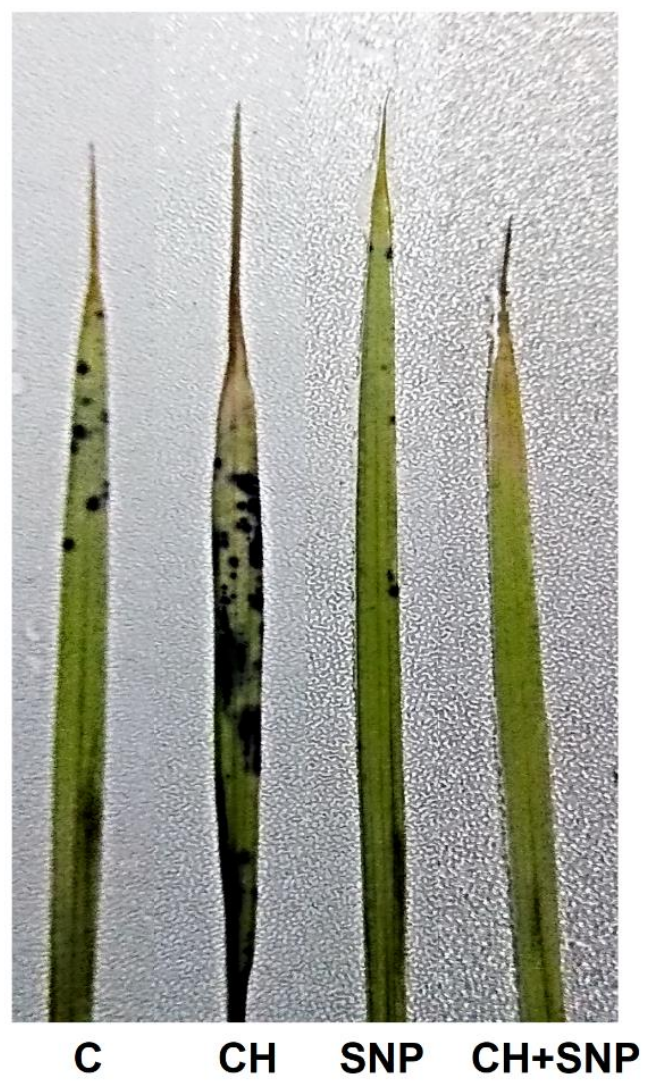

(b)

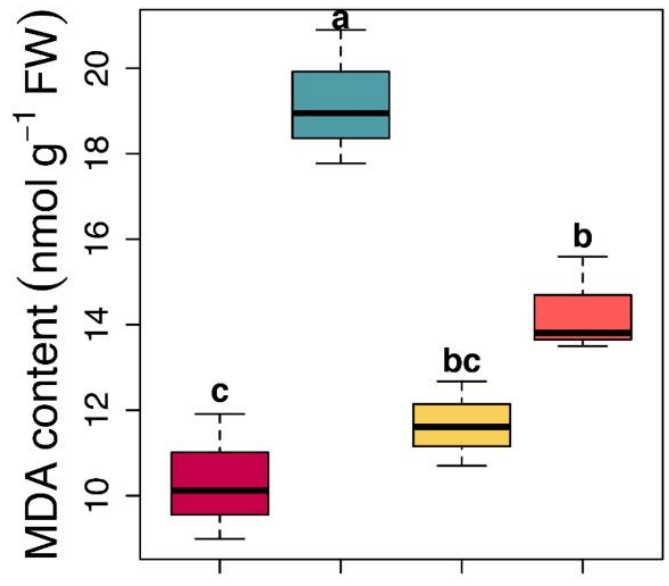

(c)

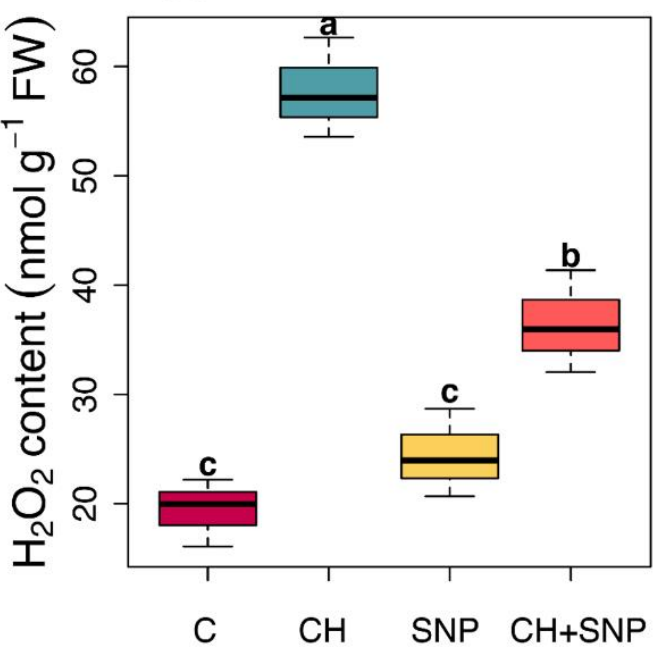

Figure 2. Effects of exogenous sodium nitroprusside (SNP) on (a) superoxide accumulation, (b) malondialdehyde (MDA) content, and (c) $\mathrm{H}_{2} \mathrm{O}_{2}$ content of rice seedlings grown under normal or chilling stress condition for 8 days. Plotted data represent the average $( \pm)$ of three independent replicates for each treatment ( $n=3$, three leaves per replicate). The vertical bar indicates the standard error. The letter on top of each bar denotes a statistically significant difference at $P<0.05$ (Tukey's honest significant differences test). "C," $0 \mathrm{~h}$ chilling day ${ }^{-1}+0 \mu \mathrm{M}$ SNP (control); " $\mathrm{CH}^{\prime}$, 8 h chilling day ${ }^{-1}+0 \mu \mathrm{M}$ SNP; "SNP", 0 h chilling day ${ }^{-1}+100 \mu \mathrm{M}$ $\mathrm{SNP}$; and “CH + SNP”, 8 h chilling day ${ }^{-1}+100 \mu \mathrm{M}$ SNP. 
(a)

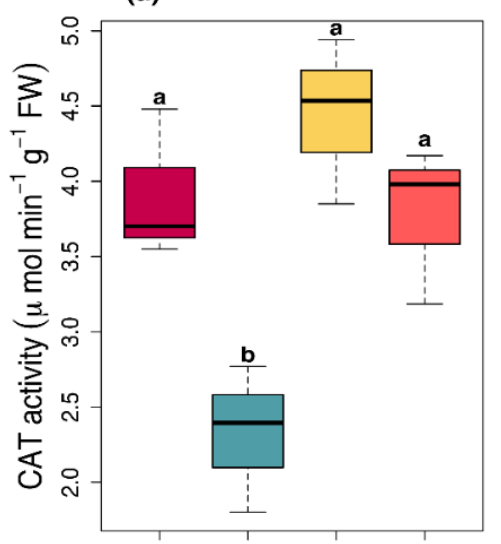

(c)

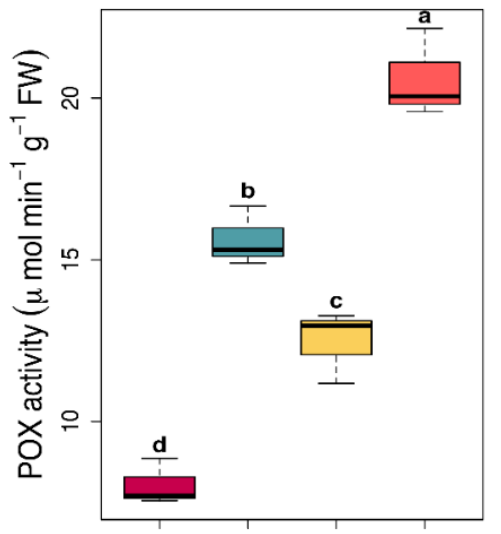

(e)

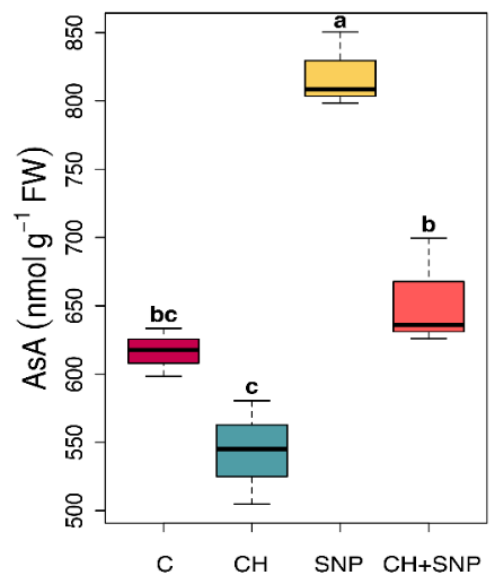

(b)

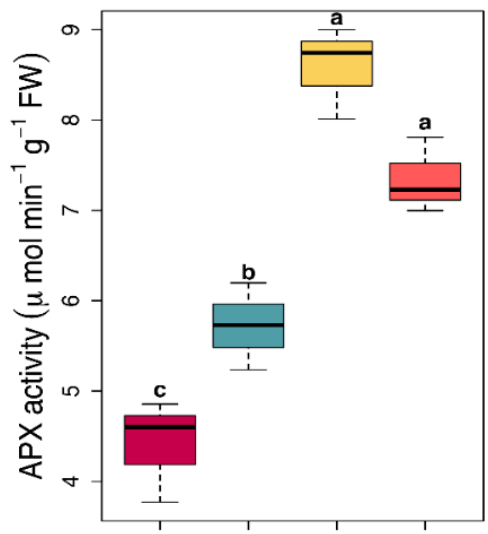

(d)
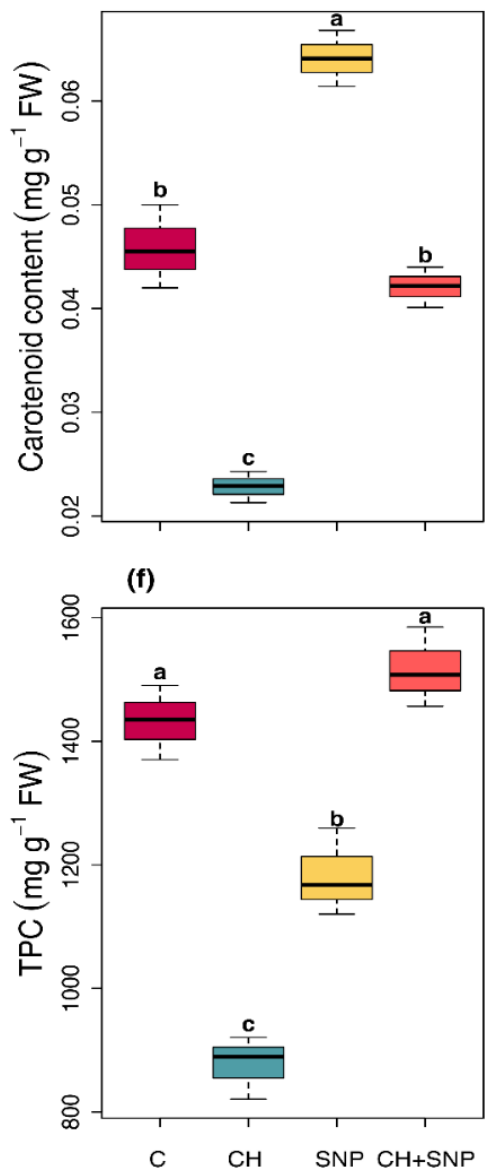

Figure 3. Effects of exogenous sodium nitroprusside (SNP) on (a) catalase (CAT) activity (b), ascorbate peroxidase (APX) activity, (c) peroxidase (POX) activity, (d) carotenoids content, (e) ascorbic acid (AsA) content, and (f) total phenolic compounds (TPC) content of rice seedlings grown under normal or chilling stress condition for 8 days. Data represented in figures are the mean $( \pm)$ of three independent replicates for each treatment ( $n=3$, three leaves per replicate). The vertical bar indicates standard error. Different letters represent significant differences at $P<0.05$ (Tukey's honest significant differences test). " $\mathrm{C}_{\text {, " } 0 \mathrm{~h}^{\mathrm{h}} \text { chilling day }}$ 1 + 0 MM SNP (control); "CH", 8 h chilling day ${ }^{-1}+0 \mu \mathrm{M}$ SNP; "SNP", 0 h chilling day ${ }^{-1}+100 \mu \mathrm{M}$ SNP; and “CH + SNP", 8 h chilling day ${ }^{-1}+100 \mu \mathrm{M}$ SNP. 


\subsection{Exogenous NO enhanced non-enzymatic antioxidants and mineral content of rice plants under chilling stress}

Several non-enzymatic antioxidants viz. AsA, carotenoids and TPC were measured to assess the role of SNP on these non-enzymatic antioxidants. In comparison with that of the control seedlings, the level of carotenoid and TPC declined significantly (by $50.18 \%$ and $38.77 \%$, respectively), whereas AsA content decreased non-significantly in chilling-stressed seedlings (Figure 3d-f). However, chilling-stressed plants supplemented with SNP showed enhancement in AsA, carotenoids, and TPC (by 20.31\%, 84.37\% and $72.94 \%$, respectively) in comparison with only chilling-stressed seedlings (Figure 3d-f). Furthermore, the application of SNP to non-stressed rice plants resulted in 32.87\% and 39.85 \% higher levels of AsA and carotenoid contents whereas $17.43 \%$ lower level of TPC as compared with that of the non-treated control rice seedling (Figure $3 \mathrm{~d}-\mathrm{f}$ ).

The $\mathrm{Na}^{+}$and $\mathrm{K}^{+}$contents were declined by $16.51 \%$ and $32.61 \%$ in chilling-stressed rice seedlings, compared with that of the control seedlings (Figure $4 \mathrm{a}, \mathrm{b}$ ). However, supplementation of SNP to chillingstressed rice seedlings showed amplification in $\mathrm{Na}^{+}$and $\mathrm{K}^{+}$contents by $24.05 \%$ and $55.77 \%$ as compared with chilling-stressed rice seedlings (Figure $4 \mathrm{a}, \mathrm{b}$ ). Then the $\mathrm{Mg}^{2+}$ and $\mathrm{Ca}^{2+}$ displayed no significant change in rice seedlings at chilling treatment relative to that of the control treatment (Figure $4 \mathrm{c}, \mathrm{d}$ ). On the other hand, supplementation with SNP to chilling-stressed seedlings showed enhanced shoot $\mathrm{Na}^{+}, \mathrm{K}^{+}, \mathrm{Mg}^{2+}$ and $\mathrm{Ca}^{2+}$ content by $24.05 \%, 55.77 \%, 7.14 \%$ and $95.06 \%$ as compared to only chilling-stressed rice seedlings (Figure 4). Moreover, in non-stressed conditions, SNP treatment showed no significant change in $\mathrm{Na}^{+}$and $\mathrm{K}^{+}$content but significant change on $\mathrm{Mg}^{2+}$ and $\mathrm{Ca}^{2+}$ content by $16.75 \%$ and $312.08 \%$ respectively as compared with that of the control condition (Figure 4).

(a)

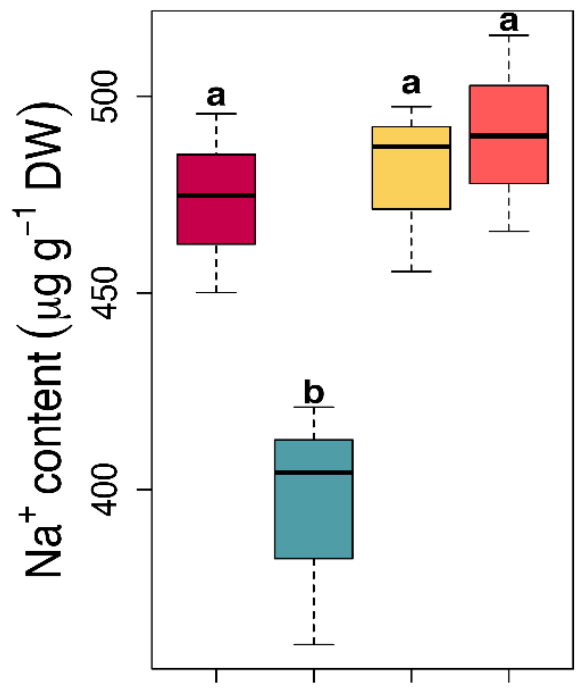

(b)

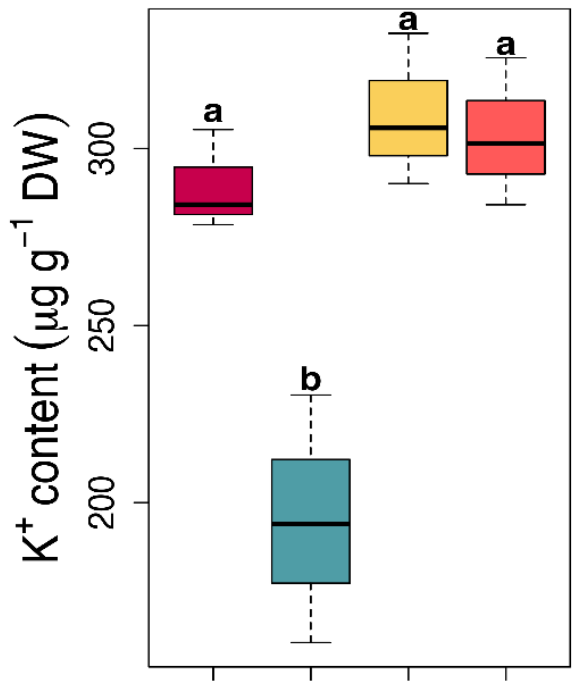


(c)

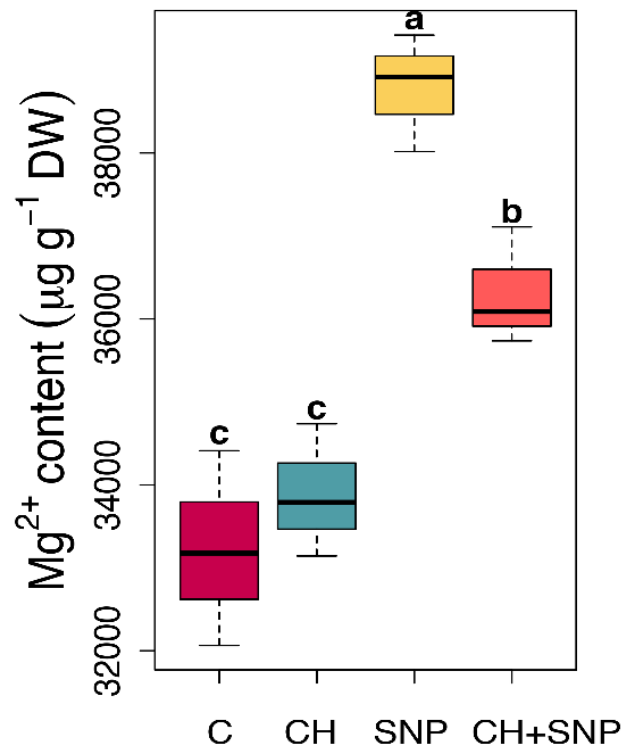

(d)

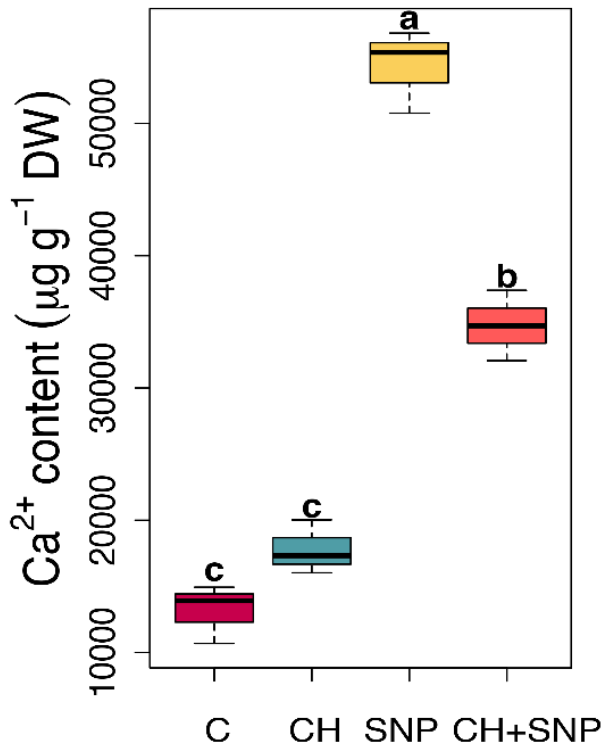

Figure 4. Effects of exogenous sodium nitroprusside (SNP) on: (a) sodium content $\left(\mathrm{Na}^{+}\right)$content (b) potassium content $\left(\mathrm{K}^{+}\right)(\mathrm{c})$ magnesium content $\left(\mathrm{Mg}^{2+}\right)$ content $(\mathrm{d})$ calcium content $\left(\mathrm{Ca}^{2+}\right)$ of rice seedlings under normal or chilling stress condition for 8 days. Data represented in figures are the mean $( \pm)$ of three replicates for each treatment ( $n=3$, three leaves per replicate). The vertical bar indicates standard error. The letter on the top of bar denotes the statistically significant difference at $P<0.05$ (Tukey's honest significant differences test). " $\mathrm{C}^{\prime \prime}$, 0 h chilling day ${ }^{-1}+0 \mu \mathrm{M}$ SNP (control); " $\mathrm{CH}^{\prime}, 8$ h chilling day ${ }^{-1}+0 \mu \mathrm{M} \mathrm{SNP}$; "SNP", 0 h chilling day ${ }^{-1}+100$ $\mu \mathrm{M}$ SNP and "CH $+\mathrm{SNP}^{\prime}, 8 \mathrm{~h}$ chilling day ${ }^{-1}+100 \mu \mathrm{M}$ SNP.

3.6. Hierarchical clustering, PCA and Correlation analysis of NO-treated rice seedling under normal and chilling conditions

Average mean values of all morpho-physiological and biochemical data were set to perform heatmap and hierarchical clustering, and PCA. Hierarchical clustering revealed the classification of these parameters into three clusters (cluster-A, cluster-B, and cluster-C) (Figure 5a). Cluster-A encompass germination indexes (PL, FGP, VI, GRI, CVG and PFW), growth-related attributes (SL, RDW, SFW and SDW), photosynthetic pigment ( $\mathrm{Chl} a, \mathrm{Chl} b$ and $\mathrm{Chl} a+b)$, antioxidants (Car, AsA, TPC and CAT), mineral contents $\left(\mathrm{Na}^{+}\right.$and $\left.\mathrm{K}^{+}\right)$and RWC of leaves of rice plants. In comparison with control, all the parameters of cluster-A displayed a decreasing trend in chilling-stressed rice plants, while an increasing trend was observed in SNP-treated chilling-stressed rice plants compared with chilling-stressed only plants (Figure 5a). Interestingly, only SNP treated non-stressed rice plants showed the highest level of increase of these parameters classified under cluster-A. The TSS, proline, $\mathrm{RaFW}, \mathrm{MDA}, \mathrm{H}_{2} \mathrm{O}_{2}, \mathrm{RL}, \mathrm{RaL}$ and MGT level in leaves were grouped in cluster-B. Compared with non-stressed treatment, Cluster-B parameters showed an increasing pattern in only chilling-treated rice plants, while they displayed a decreasing trend in SNPtreated plants and SNP-treated chilling-stressed rice plants. Cluster-C comprises $\mathrm{APX}, \mathrm{Mg}^{2+}, \mathrm{Ca}^{2+}, \mathrm{POX}$ and TSP content, which showed a moderate increase in chilling-stressed rice plants compared with control plants whereas showed the highest increase in SNP-treated chilling-stressed plants compared with only chilling-stressed rice plants.

The PCA was performed to determine the association of the morpho-physiological and biochemical parameters with the treatment groups. The PCA biplot reveals clear segregation of the four 
treatment groups $(\mathrm{C}, \mathrm{CH}, \mathrm{SNP}$ and $\mathrm{CH}+\mathrm{SNP})$ and their biological replicates. The first two PCA components combinedly explained $81.6 \%$ of the data variability (Figure 5b). SPC, POX, APX, $\mathrm{Mg}^{2+}$, and $\mathrm{Ca}^{2+}$ were loaded into the PC1, whereas CAT, Chl $a, \mathrm{Chl} b, \mathrm{Chl} a+b, \mathrm{RWC}$, PL were loaded into the PC2 (Supplementary Table 1). Results displayed that cluster-A variables were moderately and strongly associated with control and SNP treatments, respectively, whereas heatmap cluster-C variables were intensely interlinked to SNP application followed by chilling treatments. Heatmap cluster-B variables were strongly associated with chilling treatment only (Figure 5a, b).

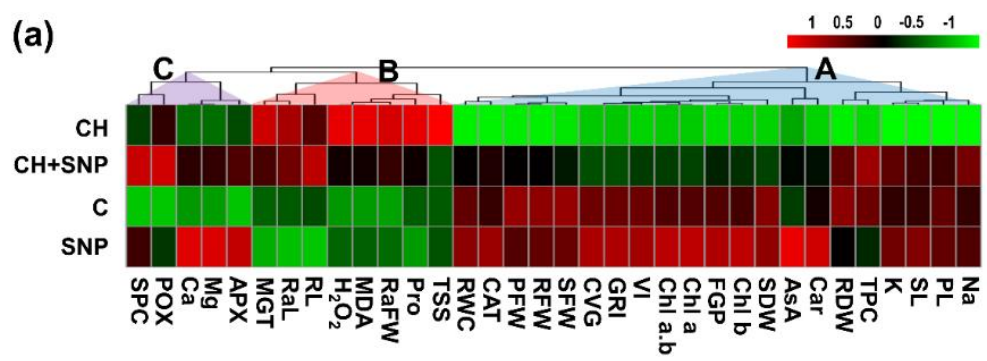

(b)

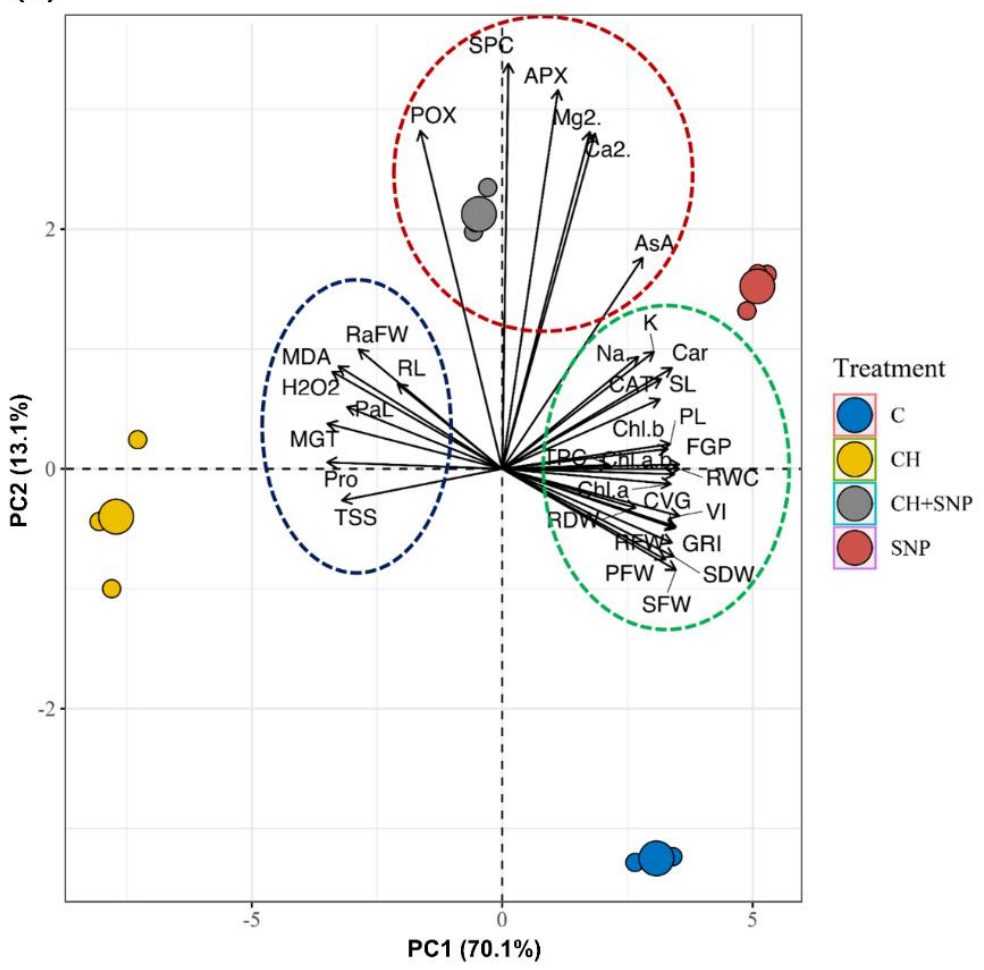

Figure 5. (a) Hierarchical clustering with heatmap and (b) principal component analysis (PCA) show the treatmentvariable relationships. In hierarchical clustering and heatmap, the mean values of various parameters obtained in this study were normalized and clustered. Three distinct clusters (cluster-A, -B and -C) were identified at the variable level. The colour scale displays the intensity of normalized mean values of different parameters. The entire dataset was analyzed using PCA. The variables included final germination percentage (FGP), mean germination time (MGT), germination rate index (GRI), coefficient of velocity of germination (CVG), vigor index (VI), shoot length (SL), root length (RL), shoot fresh weight (SFW), root fresh weight (RFW), radicle length (RaL), plumule length (PL), radicle fresh weight $(\mathrm{RaFW})$, plumule fresh weight $(\mathrm{PFW})$, catalase (CAT), ascorbate peroxidase (APX), peroxidase (POX), malondialdehyde (MDA), hydrogen peroxide $\left(\mathrm{H}_{2} \mathrm{O}_{2}\right)$, chlorophyll $a(\mathrm{Chl} a)$, chlorophyll $b(\mathrm{Chl}-b)$, chlorophyll $a+b(\mathrm{Chl}$ $a+b)$, carotenoid (Car), ascorbate (AsA), proline (Pro), total soluble sugar (TSS), total phenolic contents (TPC), soluble protein content (SPC), shoot dry weight (SDW), root dry weight (RDW), relative water content (RWC), sodium (Na), 
potassium (K), magnesium (Mg2), calcium (Ca2). " $\mathrm{C}^{\prime}$, 0 h chilling day ${ }^{-1}+0 \mu \mathrm{M} \mathrm{SNP}$ (control); “ $\mathrm{CH}^{\prime}, 8$ h chilling day$1+0 \mu \mathrm{M}$ SNP; "SNP", 0 h chilling day ${ }^{-1}+100 \mu \mathrm{M}$ SNP and " $\mathrm{CH}+\mathrm{SNP}^{\prime}, 8 \mathrm{~h}$ chilling day ${ }^{-1}+100 \mu \mathrm{M}$ SNP.

\section{Discussion}

Finding an economical and effective technique to reduce damages caused by chilling stress in rice is urgent because it causes significant yield loss. Exogenous application of some signaling molecules have enormous potentiality to reduce the deleterious effects of abiotic stresses such as chilling stresses from both theoretical and practical perspectives [52,53]. Nitric oxide (NO), a signaling molecule and secondary messenger, has been shown that to counteract with excessive ROS-induced toxicity and positively regulate many physiological processes under different stress conditions [18,54,55]. Therefore, NO could potentially be used to reduce the adverse effects of chilling stress. In the present study, we evaluated whether NO would enhance the chilling tolerance of rice seedlings when applied exogenously.

Seed germination is the first step for successful crop establishment, which critically depends on an optimum temperature, for example, $25-35^{\circ} \mathrm{C}$ for rice [27]. Usually, the temperature below the optimum level severely hampers the seed germination process [3]. In the current experiment, chilling stress $(8 \mathrm{~h}$ $5.0 \pm 1.0^{\circ} \mathrm{C}$ day $^{-1}$ ) inhibited the germination indices, such as FGP, MGT, GRI, CVG and VI (Table 1), which corroborate with the previous reports in rice under chilling and salt stress [32,56,57,58]. Priming with NO, on the other hand, successfully ameliorated chilling-induced impairment of seed germination in rice (Table 1 ). Besides, exogenous NO pretreatment enhances $\beta$-amylase activity in seeds $[59,60]$, which might contribute to improving the seed germination (Table 1).

The adverse impacts of abiotic stress on plants can be evaluated by measuring the morphological parameters such as growth and biomass of plants [61]. In the present experiment, the SL, SFW, RFW, SDW and RDW of the chilling-stressed rice plants were lower compared with that of control plants (Table 2), which perhaps occurred due to the disruption of water relation (Figure 1b), elevation of ROS content and lipid peroxidation (Figure 2) and an imbalance of ionic homeostasis (Figure 4). Exogenous application of $\mathrm{NO}$, however, recuperated the growth performance of chilling stressed rice seedling as evident by their improved phenotypic appearance (Figure 1a) and growth-related features, including SL, SFW, RFW, SDW and RDW (Table 1), perhaps by decreasing ROS accumulation and lipid peroxidation (Figure 2a, c). Moreover, NO-induced growth improvement might be ascribed to its role in increasing membrane fluidity and accelerating cell expansion processes [62]. Consistent with our results, it has also been reported that exogenous NO improved plant growth of cucumber (Cucumis sativus) [21], wheat [22] and Chinese cabbage (Brassica rapa subsp. Pekinensis) [23] under chilling stress condition. Moreover, our results were verified by PCA, which suggested that chilling-stressed rice plants that treated with NO exhibited a stronger correlation with growth-related attributes in comparison with chilling-stressed only plants (Figure 5b). Surprisingly, in the present study, RL of chilling-stressed plants increased slightly compared to the control plants (Table 2), which differs that of the findings of Fan et al. [23]. A similar increase of RL was also observed previously in Silene vulgaris under mild drought conditions [63].

The detailed study on the response of rice plants to chilling stress suggested that chilling-induced growth retardation might be due to the imbalance in ionic homeostasis. However, exogenous NO application reestablished $\mathrm{Na}^{+}$and $\mathrm{K}^{+}$balance and further increased the $\mathrm{Ca}^{2+}$ and $\mathrm{Mg}^{2+}$ contents in rice plants which might improve the growth of rice plants (Table 1; Figure 4). This finding was strongly supported by PCA results which showed a relatively stronger correlation of mineral contents with NO-treated chillingstressed plants than that with the chilling-stressed only plants (Figure 5b). Chilling stress decreased the $\mathrm{K}^{+}$ content (Figure $4 \mathrm{~b}$ ), which might trigger the partial or complete closure of stomata, thereby decreasing the water flow (Figure 1b) and $\mathrm{CO}_{2}$ assimilation [64] in rice plants, as $\mathrm{K}^{+}$is crucial for stomatal opening and closing [65]. Under lower $\mathrm{K}^{+}$level, $\mathrm{Na}^{+}$can perform some metabolic functions, due to the structural similarity of two ions in solution, thereby conferring tolerance to plants [66]. However, our results showed 
that the chilling stress decreased the $\mathrm{Na}^{+}$content in rice plants as well (Figure $4 \mathrm{a}$ ). A similar decrease of $\mathrm{Na}^{+}$ and $\mathrm{K}^{+}$contents was observed under various abiotic stress conditions $[67,68,69,70]$. Furthermore, nonstressed plants treated with $\mathrm{NO}$ showed higher accumulation of $\mathrm{Ca}^{2+}$ and $\mathrm{Mg}^{2+}$, which indicated that $\mathrm{NO}$ might upregulate the divalent cations uptake capacity of rice plants which led to the further enhancement of plant growth (Table 1; Figure 4c, d).

Along with the growth, chilling stress drastically declined the Chl pigment content (Chl $a$ and $\mathrm{Chl}$ $b$ ) as compared with that of control (Table 3). A similar decline of chlorophylls was also reported in Bermuda grass (Cynodon dactylon) [71] and Stevia rebaudiana [72] plants under chilling stress. Exogenous application of NO increased Chl content in chilling-stressed rice plants (Table 3), as also observed in Chinese cabbage [23] and cucumber [21] under chilling stress. This enhancement of Chl content occurred might be due to the elevation of the uptake and transportation of $\mathrm{Mg}^{2+}$ (Figure 4c), which is indispensable for chlorophyll synthesis [73], decreased lethal ROS and NO-mediated stability and integrity of the subcellular structures under stressed condition [74]. This enhanced Chl content might enhance the growthrelated attributes of NO-treated chilling-stressed rice plants (Table 2). Moreover, our PCA findings endorsed that chilling-exposed rice plants treated with $\mathrm{NO}$ had a stronger positive connection with Chl content than chilling-stressed only rice plants (Figure 5b).

Osmoregulation supports plants to sustain proper growth and development under stressful environments [3]. Thus, plant cell accumulates compatible solutes like proline, soluble carbohydrates, and SPC to maintain the osmotic potential and consequently retains plant water balance $[75,76,77]$. Our data revealed that only chilling-stressed plants showed a sharp accumulation of proline, TSS and SPC in rice leaves (Figure 1b, c, d), which corroborates with the findings in cold-stressed pepper (Capsicum annuum L.) [78], rice [79], Stevia rebaudiana [72], maize (Zea mays L.) [80] and wheat [81]. However, a sharp drop of RWC (Figure 1b) indicated that the increased level of these osmolytes was insufficient to alleviate the chilling effect on the growth of rice plants (Figure 1a). On the other hand, supplementation of NO allowed plants to maintain an optimum amount of water potential which consequently decreased proline and TSS content (Figure 1b, c). Moreover, we found a negative correlation between proline content and RWC (Supplementary Figure 1). On the contrary, exogenous application of NO further enhanced SPC as also observed in cucumber [82] and chickpea [24] under salinity stress.

Chilling stress alters the coordination between generation and scavenging of ROS in plant cells, thereby triggering cell death [83]. Our results showed that $\mathrm{O}_{2}{ }^{--}$and $\mathrm{H}_{2} \mathrm{O}_{2}$ contents increased in the leaves of rice plants when subjected to chilling stress (Figure 2a, c), which triggered the oxidation of membrane lipids [84], and consequently elevated MDA content (Figure 2b). Furthermore, a positive correlation was found between $\mathrm{H}_{2} \mathrm{O}_{2}$ and MDA content (Supplementary Figure 1), and our PCA results showed a strong correlation of ROS and MDA with chilling stress only treatment (Figure 5b). The enhanced production of $\mathrm{H}_{2} \mathrm{O}_{2}$ might be due to the imbalanced antioxidant enzyme activities (Figure 3a-c). These results demonstrated the adverse effects of chilling stress, i.e., stunted growth of rice seedlings through increasing ROS level and lipid peroxidation under chilling stress, that was in line with the previous studies on wheat [22,84], chickpea [85] and maize (Zea mays L.) [86]. On the other hand, exogenous application of NO to rice plants relieved adverse effects of chilling-induced oxidative stress, as supported by declined $\mathrm{O}_{2}{ }^{\bullet-}, \mathrm{H}_{2} \mathrm{O}_{2}$ and MDA contents in rice plants (Figure 2a-c), which was in accordance with previous findings in wheat [22], Chinese cabbage [23] and orange (Citrus sinensis) [87] under chilling stress. Similarly, our PCA results also confirmed that NO-treated salt-stressed treatment had a positive association with $\mathrm{H}_{2} \mathrm{O}_{2}$, MDA. However, the association prolonged to a smaller extent relative to chilling-stressed only treatment (Figure $5 b$ ), suggesting that NO treatment could reduce oxidative damages (Figure 2a-c) and facilitated improvements of growth parameters of the rice plants (Table 2). 
The increase of antioxidants activities is related to better oxidant management under stressed conditions [88,89]. In this investigation, the activities of APX and POX increased whereas CAT activity decreased in chilling-stressed plants compared with that of control plants (Figure 3a-c). The activities of these studied antioxidant enzymes were insufficient to neutralize the excess ROS, as also evident by the higher accumulation of $\mathrm{H}_{2} \mathrm{O}_{2}$ and MDA in chilling-stressed rice plants (Figure 2a-c). Consequently, growth and biomass inhibition of rice plants were evident in only chilling-stressed plants (Table 2). A similar decrease of CAT activity under chilling stress was noticed in wheat plants [84] and an increase of APX and POX were found in cucumber and wheat plants under chilling stress [22,90]. Application of NO in chillingstressed plants enhanced CAT, APX, and POX activities compared to only chilling stressed plants (Figure 3a-c). Importantly, our result showed that $\mathrm{CAT}$ and $\mathrm{H}_{2} \mathrm{O}_{2}$ negatively correlate with each other (Supplementary Figure 1), and PCA revealed that NO-treated chilling-stressed treatment had a stronger positive association with POX, APX , and CAT activity than chilling-stressed only treatment (Figure 5b). These findings revealed positive effects of exogenous NO in boosting up ROS-scavenging ability, therefore the growth of rice seedlings under chilling stress. A similar findings have been demonstrated in several plant species, such as wheat [22] and orange [87]. The current study showed that chilling stress declined the AsA, carotenoids, and TPC (Figure 3d-f); similar results were observed in rice [91] and Vitis vinifera under chilling [92,93]; tomato [94] and Solanum lycopersicum [95]under salt stress. On the other hand, the application of NO to chilling-stressed plants significantly increased AsA, TPC, and carotenoids contents (Figure 3d-f), which was also supported by PCA that showed a stronger correlation between these antioxidant content and NO-supplemented chilling-stressed treatment (Figure 5b). Several studies have also reported the NO-mediated increase in the non-enzymatic antioxidants which alleviate a wide range of abiotic stress in various plants, such as Solanum Lycopersicum [95] and tomato [94] under salt stress. Enhanced non-enzymatic antioxidants might scavenge chilling-induced ROS (Figure 2a, c), which contributed to the enhanced growth and development of rice plants (Figure 1a; Table 2).

In conclusion, our study provides the first evidence of exogenous NO-mediated chilling stress tolerance mechanisms in rice plants. The beneficial effect of NO treatments might be attributed to the alleviation of chilling stress-induced over-accumulation of ROS, possibly by enhancing the activities of ROS-scavenging enzymatic antioxidants (CAT, APX, and POX) and non-enzymatic antioxidants (AsA, TPC, and carotenoids). Moreover, exogenous application of NO was found to be effective in osmotic adjustment by modulating the contents of proline, SPC, and TSS in the rice plants growing under chilling stress, which might help in promoting water absorption and retention of rice seedlings under chilling stress. Besides, NO treatment effectively upregulate the ionic homeostasis under chilling stress. Finally, our results propose that exogenous $\mathrm{NO}$ application could be a practical and effective approach in mitigating the adverse effects of chilling stress, subsequently to ensure sustainable rice production. Further molecular studies should be carried out to gain more in-depth insight into the better understanding of the comprehensive mechanisms of NO-induced chilling stress tolerance in rice plants.

Conflict of interest: The authors declare that they have no conflict of interest.

Acknowledgements: The authors would like to extend their sincere appreciation to the Ministry of Science and Technology of Bangladesh for funding this research (Research and Development, Project No. BS-108, 2016-2017).

Author's contribution: Conceptualization: M.T-U-A., M.A.Ha. and M.G.M.; Methodology: A.A.M.S. and M.T-U-A; Software: A.A.M.S., M.T-U-A. and M.K.K.; Validation: A.A.M.S., M.T-U-A. and M.A.Ha.; Formal Analysis: S.A., A.A.M.S. and M.T-U-A.; Investigation: A.A.M.S.; Writing - Original Draft Preparation: A.A.M.S.; Writing - Review \& Editing: M.T-U-A., M.A.Ha.; M.K.K; M.S., M.B., Y.M.; Supervision: M.A.Ho.; Funding Acquisition: M.S. 


\section{References}

1. Trnka, M.; Rötter, R.P.; Ruiz-Ramos, M.; Kersebaum, K.C.; Olesen, J.E.; Žalud, Z; Semenov, M.A. Adverse weather conditions for European wheat production will become more frequent with climate change. Nat. 2014, 4, 637.

2. Onaga, G.; Wydra, K. Advances in plant tolerance to abiotic stresses. In Plant Genomics, 1st ed.; Abdurakhmonov, I.Y., Ed. Intech Open: London, UK, 2016; Volume 1, pp. 55-69.

3. Hussain, H.A.; Hussain, S.; Khaliq, A.; Ashraf, U.; Anjum, S.A.; Men, S.; Wang, L. Chilling and drought stresses in crop plants: implications, cross talk, and potential management opportunities. Front. Plant Sci. 2018, 9, 393.

4. Zinn, K.E.; Tunc-Ozdemir, M.; Harper, J.F. Temperature stress and plant sexual reproduction: uncovering the weakest links. J. Exp. Bot. 2010, 61, 1959-1968.

5. Miura, K.; Tada, Y. Regulation of water, salinity, and cold stress responses by salicylic acid. Front. Plant Sci. 2014, 5, 4 .

6. Zhang, Q.; Chen, Q.; Wang, S.; Hong, Y.; Wang, Z. Rice and cold stress: methods for its evaluation and summary of cold tolerance-related quantitative trait loci. Rice, 2014, 7, 24.

7. Tripathy, B.C.; Oelmüller, R. Reactive oxygen species generation and signaling in plants. Plant Signal Behav. 2012, 7, 1621-1633.

8. Waszczak, C.; Carmody, M.; Kangasjärvi, J. Reactive oxygen species in plant signaling. Annu. Rev. Plant Biol. 2018, 69, 209-236.

9. Kordrostami, M.; Rabiei, B. Salinity stress tolerance in plants: physiological, molecular, and biotechnological approaches. In Plant Abiotic Stress Tolerance, $1^{\text {st }}$ ed.; Hasanuzzaman, M., Hakeem, K.R., Nahar, K., Alharby, H.F. Eds.; Springer: Cham, Switzerland, 2019; Volume 1, pp. 101-127.

10. Tiwari, S. Reactive oxygen species and antioxidants: A continuous scuffle within the cell. In Reactive oxygen species in plants, 1 st ed., Singh, V.P., Singh, S., Tripathi, D.K., Prasad, S.M, Chauhan, D.K. Eds.; John Wiley \& Sons: Chichester, UK, 2017; Volume 1, pp. 187-203.

11. Iqbal, N.; Hussain, S.; Raza, M.A.; Yang, C.; Safdar, M.E.; Brestic, M.; Aziz, A.; Hayyat, M.S.; Asghar, M.A.; Yang, W.; Liu, J. Drought tolerance of soybean (Glycine max L. Merr.) by improved photosynthetic characteristics and an efficient antioxidant enzyme system under a split-root system. Front Physiol. 2019, 10, 786.

12. Caverzan, A.; Casassola, A.; Brammer, S.P. Reactive oxygen species and antioxidant enzymes involved in plant tolerance to stress. In Abiotic and biotic stress in plants- recent advances and future perspectives, Shanker, A.; Shanker, C. 1st ed.; IntechOpen: London, UK, 2016; pp. 463-480.

13. Mittler, R. ROS are good. Trends Plant Sci. 2017, 22, 11-19.

14. Mao, H.; Chen, M.; Su, Y.; Wu, N.; Yuan, M.; Yuan, S.; Brestic, M.; Zivcak, M.; Zhang, H.; Chen, Y. Comparison on photosynthesis and antioxidant defense systems in wheat with different ploidy levels and octoploid Triticale. Int. J. Mol. 2018, 19, 3006.

15. Savvides, A.; Ali, S.; Tester, M.; Fotopoulos, V. Chemical priming of plants against multiple abiotic stresses: mission possible? Trends Plant Sci. 2016, 21, 329-340.

16. Anelia, G.D. Signaling molecules in plants: exogenous application. Acta Scientific Agri. 2017, 1, 38-41.

17. Simontacchi, M.; Galatro, A.; Ramos-Artuso, F.; Santa-María, G.E. Plant survival in a changing environment: The role of nitric oxide in plant responses to abiotic stress. Front. Plant Sci. 2015, 6, 977.

18. Oz, M.T.; Eyidogan, F.; Yucel, M.; Öktem, H.A. Functional role of nitric oxide under abiotic stress conditions. In Nitric Oxide Action in Abiotic Stress Responses in Plants. Khan, 1st ed.; M.N., Mobin, M., Mohammad, F., Corpas, F.J., Eds.; Springer, Cham, Switzerland, 2015; Volume 1, pp. 21-41.

19. Fancy, N.N.; Bahlmann, A.; Loake, G.J. Nitric oxide function in plant abiotic stress. Plant, Cell Environ. 2017, 40, 462-472. 
20. Nabi, R.B.S.; Tayade, R.; Hussain, A.; Kulkarni, K.P.; Imran, Q.M.; Mun, B.G.; Yun, B.W. Nitric oxide regulates plant responses to drought, salinity, and heavy metal stress. Environ. Exp. Bot. 2019, 161, 120133.

21. Liu, X.; Wang, L.; Liu, L.; Guo, Y.; Ren, H. Alleviating effect of exogenous nitric oxide in cucumber seedling against chilling stress. Afr. J. Biotechnol. 2011, 10, 4380-4386.

22. Esim, N.;, Atici, O.; Mutlu, S. Effects of exogenous nitric oxide in wheat seedlings under chilling stress. Toxicol. Ind. Health. 2014, 30, 268-274.

23. Fan, H.; Du, C.; Xu, Y.; Wu, X. Exogenous nitric oxide improves chilling tolerance of Chinese cabbage seedlings by affecting antioxidant enzymes in leaves. Hortic. Environ. Biote. 2014, 55, 159-165.

24. Ahmad, P.; Abdel Latef, A.A.; Hashem, A.; Abd Allah, E.F.; Gucel, S.; Tran, L.S.P. Nitric oxide mitigates salt stress by regulating levels of osmolytes and antioxidant enzymes in chickpea. Front. Plant Sci. 2016, $7,347$.

25. Hasanuzzaman, M.; Nahar, K.; Hossain, M.S.; Anee, T.I.; Parvin, K.; Fujita, M. Nitric oxide pretreatment enhances antioxidant defense and glyoxalase systems to confer PEG-induced oxidative stress in rapeseed. J. Plant Interact. 2017, 12, 323-331.

26. Chaudhari, P.R.; Tamrakar, N., Singh, L., Tandon, A., Sharma, D. Rice nutritional and medicinal properties: A review. J. Pharmacogn. Phytochem. 2018, 7, 150-156.

27. Mukhopadhyay, A.; Vij, S.; Tyagi, A.K. Overexpression of a zinc-finger protein gene from rice confers tolerance to cold, dehydration, and salt stress in transgenic tobacco. Proc. Natl. Acad. Sci. 2004, 101, 6309-6314.

28. Ghadirnezhad, R.; Fallah, A. Temperature effect on yield and yield components of different rice cultivars in flowering stage. Int. J. Agron. 2014, 1-4.

29. Rashid, M.; Yasmeen, R. Cold injury and flash flood damage in boro rice cultivation in Bangladesh: A Review. Bangladesh Rice J. 2018, 21, 13-25.

30. BRRI, (Bangladesh Rice Research Institute) Adhunik Dhaner Chash (Cultivation of Modern Rice) Bangladesh Rice Research Institute, Gazipur 2017.

31. Bangladesh Meteorological Department, 2018. http://bmd.gov.bd Accessed 19 October 2018.

32. Tahjib-Ul-Arif, M.; Roy, P.R.; Sohag, A.A.M.; Afrin, S.; Rady, M.M.; Hossain, M.A. Exogenous calcium supplementation improves salinity tolerance in BRRI dhan28; a salt-susceptible high-yielding Oryza sativa cultivar. J. Crop Sci. Biotech. 2018, 21, 383-394.

33. Abdul-Baki, A.A.; Anderson, J.D. Vigor determination in soybean seed by multiple criteria 1. Crop Sci. 1973, 13, 630-633.

34. Cooper, A. The ABC of NFT. Nutrient film technique. Grower Books. 1979.

35. Tahjib-Ul-Arif, M.; Siddiqui, M.N.; Sohag, A.A.M.; Sakil, M.A.; Rahman, M.M.; Polash, M.A.S.; Mostofa, M.G.; Tran, L.S.P. Salicylic acid-mediated enhancement of photosynthesis attributes and antioxidant capacity contributes to yield improvement of maize plants under salt stress. J. Plant Growth Regul. 2018, 37, 1318-1330.

36. Lichtenthaler, H.K. Chlorophylls and carotenoids: Pigments of photosynthetic biomembranes. In Methods in Enzymology, $1^{\text {st }}$ ed.; Palfey B.A. Ed.; Elsevier: Amasterdom, Netherland, 1987; pp. 350-382.

37. Bradford, M.M. A rapid and sensitive method for the quantitation of microgram quantities of protein utilizing the principle of protein-dye binding. Anal. Biochem. 1976, 72, 248-254.

38. Velikova, V.; Yordanov, I.; Edreva, A. Oxidative stress and some antioxidant systems in acid raintreated bean plants: protective role of exogenous polyamines. Plant Sci. 2000, 151, 59-66.

39. Heath, R.L.; Packer, L. Photoperoxidation in isolated chloroplasts. Arch. Biochem. Biophys. 1968, 125, 189-198.

40. Tahjib-Ul-Arif, M.; Afrin, S.; Polash, M.A.S.; Akter, T.; Ray, S.R.; Hossain, M.T.; Hossain, M.A. Role of exogenous signaling molecules in alleviating salt-induced oxidative stress in rice (Oryza sativa L.): a comparative study. Acta Physiol. Plant. 2019, 41, 69. 
41. Zhang, Z.; Huang, R. Analysis of malondialdehyde, chlorophyll proline, soluble sugar, and glutathione content in arabidopsis seedling. Bio. Protoc. 2013, 3.

42. Ciha, A.J.; Brun, W.A. Effect of pod removal on nonstructural carbohydrate concentration in Soybean tissue. Crop Sci. 1978, 18, 773.

43. Singleton, V.L.; Rossi, J.A. Colorimetry of total phenolics with phosphomolybdic-phosphotungstic acid reagents. Am. J. Enol. Viticult. 1965, 16, 144-158.

44. Tahjib-UI-Arif, M.; Sohag, A.A.M.; Afrin, S.; Bashar, K.K.; Afrin, T.; Mahamud, A.G.M.; Polash, M.A.S.; Hossain, M.; Sohel, M.; Taher, A.; Brestic, M. Differential response of sugar beet to long-term mild to severe salinity in a soil-pot culture. Agriculture 2019, 9, 223.

45. Aebi, H. Catalase in vitro. In Methods in Enzymology. 1st ed.; Palfey, B.A., Ed.; Academic Press: Amsterdam, Netherlands, 1984, pp. 121-126.

46. Nakano, Y.; Asada, K. Hydrogen peroxide is scavenged by ascorbate-specific peroxidase in spinach chloroplasts. Plant Cell Physiol. 1981, 22, 867-880.

47. Tahjib-Ul-Arif, M.; Sayed, M.A.; Islam, M.M.; Siddiqui, M.N.; Begum, S.N.; Hossain, M.A. Screening of rice landraces (Oryza sativa L.) for seedling stage salinity tolerance using morpho-physiological and molecular markers. Acta Physiol. Plant 2018, 40, 70.

48. Schmid, R.W.; Reilley, C.N. New complexon for titration of calcium in presence of magnesium. Anal. Chem. 1957, 29, 264-268.

49. Xia, J; Wishart, D.S. Web-based inference of biological patterns, functions and pathways from metabolomic data using MetaboAnalyst. Nat. Protoc. 2011, 6, 743-760.

50. Wickham, H. ggplot2: Elegant graphics for data analysis. Springer-Verlag New York, 2016.

51. Lê, S.; Josse, J.; Husson, F. FactoMineR: an R package for multivariate analysis. J. Stat. Softw. 2008, 25, $1-18$.

52. Hayat, Q.; Hayat, S.; Irfan, M.; Ahmad, A. Effect of exogenous salicylic acid under changing environment: a review. Environ. Exp. Bot. 2010, 68, 14-25.

53. Lai, D.; Mao, Y.; Zhou, H.; Li, F.; Wu, M. Zhang, J. He, Z.; Cui, W.; Xie, Y. Endogenous hydrogen sulfide enhances salt tolerance by coupling the reestablishment of redox homeostasis and preventing saltinduced $\mathrm{K}^{+}$loss in seedlings of Medicago sativa. Plant Sci. 2014, 225, 117-129.

54. Agurla, S.; Gayatri, G.; Raghavendra, A.S. Nitric oxide as a secondary messenger during stomatal closure as a part of plant immunity response against pathogens. Nitric Oxide, 2014, 43, 89-96.

55. Astier, J.; Gross, I.; Durner, J. Nitric oxide production in plants: an update. J. Exp. Bot. 2018, 69, 34013411.

56. Ye, C.; Fukai, S.; Godwin, I.; Reinke, R.; Snell, P.; Schiller, J.; Basnayake, J. Cold tolerance in rice varieties at different growth stages. Crop Pasture Sci, 2009, 60, 328-338.

57. Wang, W.; Chen, Q.; Hussain, S.; Mei, J.; Dong, H.; Peng, S.; Huang, J.; Cui, K.; Nie, L. Pre-sowing seed treatments in direct-seeded early rice: consequences for emergence, seedling growth and associated metabolic events under chilling stress. Sci. Rep. 2016, 6, 19637.

58. Afrin, S.; Tahjib-Ul-Arif, M.; Sakil, M.; Sohag, A.A.M.; Polash, M.; Hossain, M. Hydrogen peroxide priming alleviates chilling stress in rice (Oryza sativa L.) by enhancing oxidant scavenging capacity. Fundam. Appl. Agri. 2019, 4, 713-722.

59. Zhang, H.; Shen, W.B.; Zhang, W.; Xu, L.L. A rapid response of $\beta$-amylase to nitric oxide but not gibberellin in wheat seeds during the early stage of germination. Planta 2005, 220, 708-716.

60. Duan, P.; Ding, F.; Wang, F.; Wang, B.S. Priming of seeds with nitric oxide donor sodium nitroprusside (SNP) alleviates the inhibition on wheat seed germination by salt stress. J. Plant Physiol. Mol Bio. 2007, 33, 244-250.

61. Singh, N.K.; Bracker, C.A.; Hasegawa, P.M.; Handa, A.K.; Buckel, S.; Hermodson, M.A.; Pfankoch, E.D.; Regnier, F.E.; Bressan, R.A. Characterization of osmotin: a thaumatin-like protein associated with osmotic adaptation in plant cells. Plant Physiol. 1987, 85, 529-536. 
62. Xiong, J.; An, L.; Lu, H.; Zhu, C. Exogenous nitric oxide enhances cadmium tolerance of rice by increasing pectin and hemicellulose contents in root cell wall. Planta 2009, 230, 755-765.

63. Franco, J.A.; Arreola, J.; Vicente, M.J.; Martínez-Sánchez, J.J. Nursery irrigation regimes affect the seedling characteristics of Silene vulgaris as they relate to potential performance following transplanting into semi-arid conditions. J. Hortic. Sci. Biotech. 2008, 83, 15-22.

64. Araújo, W.L.; Fernie, A.R.; Nunes-Nesi, A. Control of stomatal aperture: a renaissance of the old guard. Plant Signal Behav. 2011, 6, 1305-1311.

65. Hasanuzzaman, M.; Bhuyan, M.H.M.; Nahar, K.; Hossain, M.; Mahmud, J.A.; Hossen, M.; Masud, A.A.C.; Fujita, M. Potassium: A vital regulator of plant responses and tolerance to abiotic stresses. Agronomy 2018, 8, 31.

66. Maathuis, F.J. Sodium in plants: perception, signalling, and regulation of sodium fluxes. J. Exp. Bot. 2013, 65, 849-858.

67. Gunes, A.; Pilbeam, D.J.; Inal, A.; Coban, S. Influence of silicon on sunflower cultivars under drought stress, i: growth, antioxidant mechanisms, and lipid peroxidation. Commun. Soil Sci. Plan. 2008, 39, 1885-1903.

68. Nahar, K.; Gretzmacher, R. Effect of water stress on nutrient uptake, yield and quality of tomato (Lycopersicon esculentum Mill.) under subtropical conditions. Die Bodenkultur 2002, 53, 45-51.

69. Andrade, F.R.; da Silva, G.N.; Guimarães, K.C.; Barreto, H.B.F.; de Souza, K.R.D.; Guilherme, L.R.G.; Faquin, V.; dos Reis, A.R. Selenium protects rice plants from water deficit stress. Ecotox. Environ. Safe. 2018, 164, 562-570.

70. Kaya, C.; Tuna, L.; Higgs, D. Effect of silicon on plant growth and mineral nutrition of maize grown under water-stress conditions. J. Plant Nutr. 2006, 29, 1469-1480.

71. Fan, J.; Hu, Z.; Xie, Y.; Chan, Z.; Chen, K.; Amombo, E.; Chen, L.; Fu, J. Alleviation of cold damage to photosystem II and metabolisms by melatonin in Bermudagrass. Front. Plant Sci. 2015, 6, 925.

72. Hajihashemi, S.; Noedoost, F.; Geuns, J.M.; Djalovic, I.; Siddique, K.H. Effect of cold stress on photosynthetic traits, carbohydrates, morphology, and anatomy in nine cultivars of stevia rebaudiana. Front. Plant Sci. 2018, 9.

73. Guo, W. Magnesium homeostasis mechanisms and magnesium use efficiency in plants. In Plant Macronutrient Use Efficiency, $1^{\text {st }}$ ed.; Hossain, M.A., T Kamiya T., Burritt D., Tran L.P., Fujiwara, T. Eds.; Elsevier: Amsterdam, Netherlands, 2017; pp. 197-213.

74. Chen, F.; Wang, F.; Sun, H.; Cai, Y.; Mao, W.; Zhang, G.; Vincze, E.; Wu, F. Genotype-dependent effect of exogenous nitric oxide on $\mathrm{Cd}$-induced changes in antioxidative metabolism, ultrastructure, and photosynthetic performance in barley seedlings (Hordeum vulgare). J. Plant Growth Regul. 2010, 29, 394408.

75. Zivcak, M.; Brestic, M.; Sytar, O. Osmotic adjustment and plant adaptation to drought stress. In Drought Stress Tolerance in Plants, $1^{\text {st }}$ ed.; Hossain, M.A., Wani, S.H., Bhattacharjee, S., Burritt, D.J., Tran, L.-S.P., Eds.; Springer International Publishing: Cham, Switzerland, 2016; Volume 1, pp. 105-143.

76. Mansour, M.M.F.; Ali, E.F. Evaluation of proline functions in saline conditions. Phytochem. 2017, 140, 52-68.

77. Hasanuzzaman, M.; Anee, T.I.; Bhuiyan, T.F.; Nahar, K.; Fujita, M. Emerging role of osmolytes in enhancing abiotic stress tolerance in rice. In Advances in Rice Research for Abiotic Stress Tolerance, $1^{\text {st }}$ ed. Hasanuzzaman, M., Fujita, M., Nahar, K., Biswas, J.K. Eds.; Elsevier: Amsterdam, Netherland, 2019; pp. 677-708.

78. Esra, K.O.Ç; İŞLEK, C.; Üstün, A.S. Effect of cold on protein, proline, phenolic compounds and chlorophyll content of two pepper (Capsicum annuum L.) varieties. Gazi Univ. J. Sci. 2010, 23, 1-6.

79. Ghosh, T.; Rai, M.; Tyagi, W.; Challam, C. Seedling stage low temperature response in tolerant and susceptible rice genotypes suggests role of relative water content and members of OsSNAC gene family. Plant Signal Behav. 2016, 11, p.e1138192. 
80. Li, Z.; Xu, J.; Gao, Y.; Wang, C.; Guo, G.; Luo, Y.; Huang, Y.; Hu, W.; Sheteiwy, M.S.; Guan, Y.; Hu, J.. The synergistic priming effect of exogenous salicylic acid and $\mathrm{H}_{2} \mathrm{O}_{2}$ on chilling tolerance enhancement during maize (Zea mays L.) seed germination. Front. Plant Sci. 2017, 8, 1153.

81. Karimzadeh, G.; Sharifi-Sirchi, G.R.; Jalali-Javaran, M.; Dehghani, H.; Francis, D. Soluble proteins induced by low temperature treatment in the leaves of spring and winter wheat cultivars. Pak. J. Bot. 2006, 38, 1015.

82. Fan, H-F.; Du, C-X.; Guo, S-R. Effect of nitric oxide on proline metabolism in cucumber seedlings under salinity stress. J. Am. Soc. Hortic. Sci. 2012, 137, 127-133.

83. Choudhury, F.K.; Rivero, R.M.; Blumwald, E.; Mittler, R. Reactive oxygen species, abiotic stress and stress combination. Plant J. 2017, 90, 856-867.

84. Abdel Kader, D.Z.; Saleh, A.A.; Elmeleigy, S.A.; Dosoky, N.S. Chilling-induced oxidative stress and polyamines regulatory role in two wheat varieties. J. Taibah Univ. Sci. 2011, 5, 14-24.

85. Yousefi, V.; Ahmadi, J.; Sadeghzadeh-Ahari, D.; Esfandiari, E. Influence of long-term cold stress on enzymatic antioxidative defense system in chickpea (Cicer arietinum L.). Acta Agrobot. 2018, 71, 3.

86. Esim, N.; ATICI, Ö. Relationships between some endogenous signal compounds and the antioxidantsystem in response to chilling stress in maize (Zea mays L.) seedlings. Turk. J. Bot. 2016, 40, 37-44.

87. Ghorbani, B.; Pakkish, Z.; Khezri, M. Nitric oxide increases antioxidant enzyme activity and reduces chilling injury in orange fruit during storage. New Zeal J. Crop Hort. 2018, 46, 101-116.

88. Ahmad, P.; Jaleel, C.A.; Salem, M.A.; Nabi, G.; Sharma, S. Roles of enzymatic and nonenzymatic antioxidants in plants during abiotic stress. Crit. Rev. Biotechnol. 2010; 30, 161-175.

89. Engwa G.A. Free radicals and the role of plant phytochemicals as antioxidants against oxidative stressrelated diseases. In Phytochemicals - Source of Antioxidants and Role in Disease Prevention, 1st ed.; Asao, T., Asaduzzaman, M. Eds.; Intech Open: London, UK, 2016; pp. 211-228.

90. Lee, D.H.; Lee, C.B. Chilling stress-induced changes of antioxidant enzymes in the leaves of cucumber: in gel enzyme activity assays. Plant Sci. 2000, 159, 75-85.

91. Huang, M.; Guo, Z. Responses of antioxidative system to chilling stress in two rice cultivars differing in sensitivity. Biol. Plant. 2005, 49, 81-84.

92. Król, A.; Amarowicz, R.; Weidner, S. Changes in the composition of phenolic compounds and antioxidant properties of grapevine roots and leaves (Vitis vinifera L.) under continuous of long-term drought stress. Acta Physiol. Plant. 2014, 36, 1491-1499.

93. Król, A.; Amarowicz, R.; Weidner, S. The effects of cold stress on the phenolic compounds and antioxidant capacity of grapevine (Vitis vinifera L.) leaves. J. Plant Physiol. 2015, 189, 97-104.

94. Ali, H.E.M.; Ismail, G.S.M. Tomato fruit quality as influenced by salinity and nitric oxide. Turk. J. Biol. 2014, 38, 122-129.

95. Aflaki, F.; Sedghi, M.; Pazuki, A.; Pessarakli, M. Investigation of seed germination indices for early selection of salinity tolerant genotypes: a case study in wheat. Emir. J. Food Agr. 2017, 29, 222-226. 